\title{
Wellbeing Trajectories around Life Events in Australia
}

\author{
Nigel O'Leary \\ Swansea University, and WISERD \\ School of Management, Swansea University \\ Swansea SA1 8EN \\ UK \\ TEL: +44 1792602113 \\ E-mail: n.c.oleary@swansea.ac.uk \\ Ian W. Li \\ School of Population and Global Health, The University of Western Australia \\ Perth, WA 6009 \\ E-mail: ian.li@uwa.edu.au \\ Prashant Gupta \\ Department of Accountancy and Finance, Brunel University London \\ E-mail: prashant.gupta@brunel.ac.uk \\ David Blackaby \\ Swansea University, and WISERD \\ School of Management, Swansea University \\ E-mail: d.h.blackaby@swansea.ac.uk
}

\begin{abstract}
Wellbeing trajectories around key life events are calculated using HILDA data for Australia. Employing a panel quantile approach, a pan-distributional analysis of these major events identifies distinctive adjustment patterns across the subjective wellbeing distribution and differing orders of magnitudes. For all life aspects analysed, immediate impacts tend to be more acute at the lower end of the wellbeing distribution. The implication of this is that if we are concerned with measuring changes in wellbeing, the point at which we measure these changes is important. Given the increasing importance of wellbeing to broader measures of economic prosperity, these findings touch upon a number of important policy areas. A focus upon social ostracization and a reduction in the persistence of long-term unemployment are all suggested as ways of alleviating the detrimental impact of this important policy variable.
\end{abstract}

Keywords: subjective wellbeing; anticipation; adaption; quantile regression.

JEL: $131 ; \mathrm{J} 01$

\section{Acknowledgements}

This paper uses unit record data from the Household, Income and Labour Dynamics in Australia (HILDA) Survey. The HILDA Project was initiated and is funded by the Australian Government Department of Social Services (DSS) and is managed by the Melbourne Institute of Applied Economic and Social Research (Melbourne Institute). The views reported here, however, are solely those of the authors. Financial support from the ESRC (grant no: ES/L009099/1 and ES/S012435/1) is acknowledged by Blackaby and O'Leary. Li acknowledges funding from the Faculty of Health and Medical Sciences, The University of Western Australia which supported a visiting scholarship to Swansea University. 


\section{Introduction}

Wellbeing is about feeling good and functioning well and encapsulates individuals' experiences of their lives and a comparison of their circumstances with social norms and values. Within this context, there is a rapidly expanding area of empirical research that looks at the determinants and consequences of reported happiness or life satisfaction, commonly referred to as subjective wellbeing. In one of the first broad reviews of subjective wellbeing by Wilson (1967), someone with high wellbeing emerged "as a young, healthy, well-educated, well-paid, extroverted, optimistic, worry-free, religious, married person, with high self-esteem, high job moral, modest aspirations, of either sex and of a wide range of intelligence" (p. 294). In a wide-ranging literature that has developed since this initial review of Wilson, the determinants of wellbeing are well understood at both the micro- (see inter alia Ferrer-iCarbonell and Frijters, 2004) and macro- (see inter alia Helliwell, 2003) levels, although research has broadened to encompass not only the characteristics and correlates of wellbeing, but also the underlying processes and causal pathways (see Layard et al, 2014 and Heady and Muffels, 2017 inter alia) and whether high levels of wellbeing are beneficial to effective functioning. Within this context, a body of evidence suggests that higher wellbeing improves life in the areas of health and longevity, work and income, social relations, and benefits to society (see Diener and Biswas-Diener, 2008 for an extensive review).

At a policy level, the importance of such subjective measures of wellbeing has assumed increased importance and the deficiencies of (traditional) income-based measures of wellbeing such as GDP are well-recognised (see inter alia Stiglitz et al., 2009, ONS, 2011). Indeed, McGregor and Pouw (2017) highlight the growing concern that currently dominant economic frameworks are no longer able to address adequately the problems of a rapidly changing globalised world, suggesting a reframing towards a much clearer focus upon wellbeing. Such sentiments resonate with earlier calls to utilise "national accounts of well-being to monitor well-being within nations, with a view to increasing wellbeing and improving societal conditions." (Diener and Ryan, 2009, p. 400). 
Within such a paradigm, crucial questions are raised as to how and whether individuals adapt to changing conditions. If they do, then this leads to the phenomenon originally proposed by Brickman and Campbell (1971) that is referred to as the hedonic treadmill, where circumstances (and how these change) do not matter in the long run to wellbeing as individuals adapt to the point of affective neutrality through readjustment of their evaluative standards. Such a viewpoint - set-point theory has come under increasing challenge as evidence has emerged form national panel surveys that substantial minorities of respondents record large long-term changes in their life satisfaction (see Heady et al, 2010, 2013 inter alia). But regardless of the theoretical underpinning and whether wellbeing is perceived as an inherently stable or volatile concept, a consistent picture has emerged in the empirical literature that wellbeing is affected by life events (see Heady and Muffels, 2017 for a reasoning of why these changes occur over short, medium and long-run horizons). Knowing the magnitude of adaptation effects to changing conditions would be of value to policy makers in plotting the trajectories of wellbeing over time. Indeed, previously discussed applications of wellbeing in the existing literature include applications in health policy, such as establishing the monetary value of a health condition, legal compensation, or for welfare frameworks in general (McNamee and Mendolia, 2014; Oswald and Powdthavee, 2008).

Setting out a methodological framework that a number of subsequent studies have adopted, Clark et al. (2008) investigated wellbeing trajectories over six life history events using longitudinal German data. Motivated by the work of Binder and Coad (2011) which emphasises the entirety of the subjective wellbeing distribution, Gupta et al. (2015) implemented a quantile estimator to extend their investigation of the impact of illness across the wellbeing distribution in Britain. Our own work will extend this line of analysis by employing a quantile framework that allows adaption to anticipation to life events to be identified using Australian data and this extends the mean-based empirical evidence available for Australia by Frijters et al. (2011) and Anusic et al. (2014). In doing so, evidence will be presented for not only those with typical responses around the middle of the wellbeing distribution but also for some of the most satisfied and some of the least satisfied individuals within society. Might 
those assumed to be the most emotionally vulnerable who report lower levels of wellbeing be impacted differently by changing life events? And might it not be conjectured that the most emotionally robust who report higher levels of wellbeing might in some way be more resilient to changing circumstances? Only by looking across the wellbeing distribution as we do here can a picture of the entire population be drawn.

However, empirical measures of subjective wellbeing that are available within commonly used datasets often exhibit a lack of variation in reported outcomes and do not lend themselves to pandistributional quantile estimation. We adapt the quantile count approach of Machado and Santos Silva (2005) to overcome this problem and implement their approach within the conditional panel quantile setting proposed by Koenker (2004). In addition to providing unique estimates for Australia and providing an update on the limited empirical evidence that is available even at mean levels from which relevant and timely policy conclusions can be drawn, the approach also offers a convenient solution in alternative datasets to deriving quantile estimates when there is limited variation in reported wellbeing.

The remainder of the paper is therefore organised as follows. Section 2 reviews the most relevant background literature and section 3 briefly describes the HILDA dataset that is used for the empirical estimation. With the methodological framework being set out in section 4, results are presented in section 5 before concluding comments and associated policy implications are given in section 6 .

\section{Some Background}

Clark et al. (2008) investigated the dynamics of wellbeing over six aspects of employment status, marriage and childbirth using longitudinal German data, and in a closely related studies Clark and Georgellis (2013) analysed comparable factors using British data and Bauer et al. (2015) have used Russian data over four aspects of unemployment and marital status. For Australia, Frijters et al. (2011) used a short panel to address adaption to marriage, divorce, birth of a child, injury/illness, death of 
spouse or child, being a victim of crime, redundancy, change in financial situation and change in residence. Across these studies there is some evidence (although not universal over all life event aspects) to suggest that wellbeing impacts caused by changing life circumstances are short-lived and individuals returned to a baseline level of wellbeing. Such findings are also consistent with the earlier work of Headey and Wearing (1989) who followed a group of respondents in Australia for a period of eight years and found that people initially reacted strongly to pleasant and unpleasant events but then returned toward their original baseline wellbeing levels.

In addition to the broad multi-dimensional analyses already mentioned, a number of studies have also detailed specific life event episodes although employing alternative methodologies to those of the multi-event analyses. For marriage, Lucas et al. (2003) and Lucas and Clark (2006) find that those who get married report short-term wellbeing increases followed by complete adaption back to baseline levels. In contrast to these, Qari (2014) shows that individuals who decide to marry become permanently happier. All three studies use German data. For the onset of a disability, Oswald and Powdthavee (2008) find that adaption reverts to pre-disability wellbeing levels using British data. Similar conclusions are drawn by Gupta et al. (2015), who looked at the onset of a spell of illness (which may include a disability) also using British data. These stand in contrast to Lucas (2007), who concludes that there is no disability adaption. Further, Binder and Coad (2013) show that the impact of health impairments on wellbeing is heterogenous across illness type and that adaption also varies by impairment for Britain. Asymmetries in wellbeing effects are also identified for a deterioration in health and health improvements. For the birth of a child, Myrskylä and Margolis (2014) find for Germany and Britain that happiness increases in the years around the birth of a first child and then subsequently decreases to before-child levels. For divorce, Lucas (2005) finds evidence of a rapid adaption using German data and Gardner and Oswald (2006) find a comparable result for Britain. For unemployment, Lucas et al. (2004) use German data and find only partial recovering from an initial negative impact, mirroring much of the multi-event results previously cited. For widowhood, Bonanno et al. $(2002,2004)$ show that emotional reactions rebound eventually after the death of a spouse. 
While such a body of evidence mimics the life events studied here, it is by no means an exhaustive list. Inter alia, in a seminal and oft-cited paper Brickman et al. (1978) examine the wellbeing of lottery winners and individuals with spinal cord injuries. Similarly, Silver (1982) also examines the adaption of those with spinal cord injuries. More recently, Ferrer-i-Carbonell and Van Praag (2008) focus upon adaption to income changes and McNamee and Mendolia (2014) find that the negative effect of chronic pain receded slightly for those with this condition over an extended period of time. And in a pan-European study of inter-generational co-residence, Tosi and Grundy (2018) find that returns by adult children to the parental home were associated with decreases in the wellbeing of parents. ${ }^{1}$

\section{Data}

The data used are of individuals taken from the first fourteen waves of the Household, Income and Labour Dynamics in Australia (HILDA), an annual survey of households conducted since 2001. A household panel survey, HILDA also collects a wide range of information on individuals, such as their earnings, family relations, education, employment backgrounds, and demographic characteristics. In addition, it offers broad information on various wellbeing indicators and the central variable for our analysis is overall life satisfaction. As such, all individuals within the household are asked the question: 'How satisfied are you with your life?". Responses to this question are recorded on a scale of 0 (totally dissatisfied) to 10 (totally satisfied). As is commonly observed with such questions, there is a distinct positive skew to responses. The modal category is 8 , the response given by approximately one third of respondents, and a further one third return scores in the top two bands (of 9 and 10). Only a little over one in eight respondents report a value of 6 or below.

\footnotetext{
${ }^{1}$ Such a body of evidence sits within a wider-ranging literature that has looked at wellbeing more generally. Examples of this within the Australian context have shown: declining life satisfaction over time and a diminishing gap between males and females (Ambrey and Fleming, 2014); economic and social factors at the neighbourhood level impacting upon life satisfaction (Shields, Wheatly Price and Wooden, 2009); and wellbeing differentials across disadvantaged groups such as sexual minorities (Powdthavee and Wooden, 2015) and the indigenous population (Manning, Ambrey and Fleming, 2016)
} 
To create event histories across five different major life aspects (illness, marriage, widowhood, birth of a child and unemployment), the data are restricted in a specific way to create five unique samples. The crucial aspect that dictates the creation of these event histories is that an initial incidence of the event (be that illness, unemployment etc.) is taken for each individual within HILDA which is preceded by at least one wave in which the event is not reported. This means that the transition into the life event is always observed and this lead-in period creates a clear measure of anticipation to the event and removes the risk of conflating anticipation effects with multiple occurrences of the event. For clarity, this structure before the event take place is represented schematically in Appendix Figure 1 (panel a). After the first reported incidence, individuals are retained within the sample for the next five waves regardless of whether they continue to report the event. The only proviso is that once individuals do not report the event after the initial incidence they are excluded if they subsequently re-report the event. This again provides a clean measure of the event and any identified adaption effects will not be conflated with multiple event spells and anticipation of them. Thus, individuals are identified in their transition into the first occurrence of the life event and then have a complete history for the next five years. This post-event structure is represented schematically in Appendix Figure 1 (panel b). This shows permissible patterns within the data as just described, with the implication that any other combinations after the event are excluded from the analysis. In this sense, the panel is balanced to the right of the observed life event. However, the panel is unbalanced to the left, in that some individuals will only be observed in the data one year before the event, some two years before the event and so on. ${ }^{2}$ This leaves a sample of between 33,061-75,659 men and women observed annually in an unbalanced panel over the age of 16 depending upon the precise event being studied, with the crucial consideration that there are no gaps in the reported event histories. ${ }^{3}$

\footnotetext{
${ }^{2}$ With 4 possible combinations before the event and 6 possible combinations after, this implies that one of 24 distinct permutations must exist within the data to be eligible to make up one of the event histories.

${ }^{3}$ For the analysis of birth of a child, the sample is restricted to those aged 40 and under at time of birth. For the unemployment analysis, the sample is restricted to individuals who are 50 or less to avoid overlapping with early voluntary retirement which is available between the ages of 55 and 60 with access to superannuation or the age pension. For all other event histories, we include individuals up to the age of 80 .
} 


\section{Methodology}

A central contribution of this paper in the literature of subjective wellbeing is to capture the heterogeneous effect of various life events across the life satisfaction distribution, and this can only be achieved if one uses an estimation technique such as quantile regression. However, one of the important requirements in quantile regression estimation is continuity of the dependent variable so that one can make an inference of the shape of the outcome variable. If the individual response, in our case life satisfaction, is recorded as discrete data with little natural variation then it does not satisfy the necessary condition of continuity per se. To overcome this problem, Machado and Santos Silva (2005) suggest using a data smoothing technique that provides a natural way to use count responses within a quantile framework. Under this methodology, a small imputation - jittering - is applied to achieve the continuity in the dependent variable by adding a smoothing parameter $u$ for individual $i$ at time $t$, without conditioning on control variables, leading to a new variable in the following way:

$$
Z_{i t}=\text { lifesat }_{i t}+u_{i t}
$$

where lifesat is the discrete survey response to the life satisfaction question, with $u$ being independent of lifesat and uniformly distributed in the interval of $[0,1]$, and this new transformation produces a continuous variable whose distribution is smooth almost everywhere. A monotonic transformation can then be applied to $Z_{i t}$ which ensures that estimated quantiles of $Z_{i t}$ are non-negative and that these transformed quantiles are linear in parameters. To do this, a transformation $T\left(Z_{i t}, \alpha\right)$ and its associated representation of the conditional $\alpha$-quantile of $Z_{i t}$ must be specified. This conditional representation is denoted as $Q_{Z_{i t}}\left(\alpha \mid X_{i t}\right)$, where $X_{i t}$ represents a vector of observable characteristics. Thus

$$
T\left(Z_{i t}, \alpha\right)= \begin{cases}\log Z_{i t}-\alpha & \text { for } Z_{i t}>\alpha \\ \log \zeta & \text { for } Z_{i t} \leq \alpha\end{cases}
$$

and

$$
Q_{Z_{i t}}\left(\alpha \mid X_{i t}\right)=\alpha+\exp \left[x_{i}^{\prime} \beta(\alpha)\right]
$$


where $\zeta$ is a small positive number. The vector of parameters $\beta(\alpha)$ is estimated by means of standard quantile regression of $T\left(Z_{i t}, \alpha\right)$ on the vector of explanatory variables $X_{i t}$. This new transformation of variable $Z$ is then utilised in a quantile regression framework to capture the heterogeneous effect of various life events across the distribution by implementing the conditional quantile regression panel fixed effect framework developed by Koenker (2004). Using this, we extend the framework of anticipation and adaption proposed by Clark and Georgellis (2013) to analyse how illness, marriage, widowhood, birth of a child and unemployment (individually) affect life satisfaction at various percentile points across the wellbeing distribution. This is done by introducing a set of time-specific dummy variables for individual $i$ at time $t$ to capture adaption and anticipation to an event at percentile $\tau$ :

$$
\begin{aligned}
& Q_{Z_{i t}}=\gamma_{i}^{\tau}+X_{i t}^{\prime} \beta^{\tau}+I_{-4, i t}^{\prime} \rho_{-4}^{\tau}+I_{-3, i t}^{\prime} \rho_{-3}^{\tau}+I_{-2, i t}^{\prime} \rho_{-2}^{\tau}+I_{-1, i t}^{\prime} \rho_{-1}^{\tau}+I_{0, i t}^{\prime} \rho_{0}^{\tau}+ \\
& I_{1, i t}^{\prime} \rho_{1}^{\tau}+I_{2, i t}^{\prime} \rho_{2}^{\tau}+I_{3, i t}^{\prime} \rho_{3}^{\tau}+I_{4, i t}^{\prime} \rho_{4}^{\tau}+I_{5+, i t}^{\prime} \rho_{5}^{\tau}+\epsilon_{i t}
\end{aligned}
$$

where $\gamma_{i}$ corresponds to a vector of time-invariant individual-specific effects (i.e. the 'fixed effects'), $\epsilon_{i t}$ a disturbance term and $I$ the dummy variables reflecting event duration: for anticipation $\left(I_{-4, i t}\right.$ to $I_{-}$ $\left.{ }_{1, i t}\right)$, these denote 4 years to 1 year before the initial event incidence at time $\left(I_{0}\right)$; for adaption $\left(I_{1, i t}\right.$ to $\left.I_{5+, i t}\right)$, these denote that the event has persisted for an additional number of years ranging from 1 to 5+. The estimated coefficients in $\rho$ then measure adaption and anticipation effects relative to a baseline of those who do not report the event more than four years before the initial incidence.

\section{Results}

By way of background, Table 1 presents the number of observations at each point in time for each of the events. Looking at the lower half of the table initially, the figures show the number of individuals reporting the first occurrence of an event at time $t$ and then its subsequent persistence. Thus, the most commonly observed event is illness (of which there are 2,784 initial episodes) and the least commonly observed is widowhood (with 598 episodes). With regards persistence, this is most keenly 
observed with marriage. Of the 1,467 individuals becoming married at time $t$, nearly two thirds of them are still married four years after the event (at time $t+4$ ). Contrast this with the 2,215 individuals who are unemployed at time $t$ and of whom 221 remain unemployed at $t+2 .{ }^{4}$

\begin{tabular}{|c|c|c|c|c|c|c|c|}
\hline & & & Illness & Marriage & Widowhood & Birth of Child & Unemployment \\
\hline \multirow{5}{*}{ 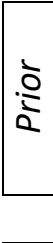 } & $t-4$ & $3-4$ years & 2122 & 1292 & 375 & 1488 & 916 \\
\hline & $t-3$ & $2-3$ years & 2741 & 1641 & 455 & 1743 & 1212 \\
\hline & $t-2$ & $1-2$ years & 3850 & 2016 & 515 & 2299 & 1604 \\
\hline & $t-1$ & $1-0$ years & 4199 & 2593 & 636 & 2921 & 2242 \\
\hline & $t$ & At the event & 2784 & 1467 & 598 & 2535 & 2215 \\
\hline \multirow{5}{*}{ 產 } & $t+1$ & $1-2$ years & 1505 & 1367 & 380 & 2449 & 567 \\
\hline & $t+2$ & $2-3$ years & 726 & 1289 & 298 & 1831 & 221 \\
\hline & $t+3$ & $3-4$ years & 408 & 1090 & 205 & 1411 & 111 \\
\hline & $t+4$ & 4-5 years & 310 & 917 & 150 & 1083 & 53 \\
\hline & $t+5+$ & $5+$ years & 441 & 1347 & 196 & 3383 & 83 \\
\hline
\end{tabular}

Table 1: Number of Lag and Lead Observations by Life Event

Underpinning the anticipation and adaption effects from equation [4] defined previously is the estimation of fixed effects regressions of life satisfaction on a number of factors which have been commonly used in life satisfaction studies and which are available within the data i.e. the vector of explanatory $X_{i t}$ as previously defined. While Ferrer-i-Carbonnel and Frijters (2004) conclude that the majority of controls that have been included in empirical wellbeing analyses do not unduly influence estimates, the use of a fixed effects estimator, to control for individual specific unobserved heterogeneity, is important. Failure to do so significantly reduces the coefficients associated with wellbeing determination. Hence, we employ a fixed effects estimator in conjunction with our range of control variables, precise details of which are given in Appendix Table 1. While it is not feasible to give a blow by blow account of all regressions over all life event aspects, the results did conform to a priori

\footnotetext{
${ }^{4}$ The Australian economy has been characterized by reduced macroeconomic volatility over the past 40 years (Cross, 2019) and for both men and women there are substantial outflows from unemployment from any given year to the next as identified within HILDA. Between 2001 and 2014, well over $40 \%$ of men exited from unemployment into employment each year and consistently over $20 \%$ of them transitioned from unemployment to not being in the labour force. The comparable figures for women are close to $50 \%$ (to employment) and close to $30 \%$ (to out of the labour force) (see Melbourne Institute, 2016). While we do not seek to explain the reasons behind these transitions, they show that persistent long-term unemployment has not been a common phenomenon over this period, as reflected in our own figures from Table 1. However, such figures do need to put into perspective. As such, while $45 \%$ of the long-term unemployed who accessed Jobactive, the government's employment service, were able to find a job within three months in $2016 / 17,38 \%$ of these positions were casual and $62 \%$ of them were part-time (ACOSS, 2018).
} 
expectations and are in line with the existing literature. As such, life satisfaction increases with income and decreases with age, number of dependent children and poorer health. Equally, reported satisfaction also shows substantial variation across employment status (being greatest for those in retirement and lowest for those unemployed), marital status (being greatest for those who are married and lowest for those who are separated), and educational categories (but generally increases with educational attainment). Further, there are also substantial variations in wellbeing across states and by remoteness indicator, although these locational patterns vary by the life event aspect being analysed. ${ }^{5}$

In what follows, we will individually discuss the five life events at five distinct percentile points. Such results are presented graphically in Figure 1 (panels a-e) for each of the events separately. The underlying coefficient estimates and associated standard errors that underpin these Figures are reported in Appendix Table 2.

\section{$5.1 \quad$ IIlness}

In Figure 1 (panel a), the anticipation and adaptation effects of illness on life satisfaction are presented for selected quantiles. ${ }^{6}$ Studies related to health and wellbeing consistently reveal a strong relationship between the two (see Dolan et al., 2008 for a review) and observe that causality runs in both directions, with high levels of wellbeing relevant for subsequent good health (see Binder and Coad, 2010). However, the more prominent relationship seems to run from health to wellbeing and numerous studies show that healthier individuals tend to be happier, whether that be in terms of

\footnotetext{
${ }^{5}$ While the use of a fixed effects estimator will pick up unobserved heterogeneity such as personality traits, it also captures observable characteristics that are fixed. Hence, observable traits such as gender and ethnic background are not included as control variables and such influences are instead picked up in the time-invariant fixed effect. In a similar way, we do not explicitly control for relative income and social comparison effects (see Paul and Guilbert (2013) for an investigation within an Australian context) as such influences will also be taken out as a fixed effect.

${ }^{6}$ In what follows, illness is taken as any response to a series of questions asking respondents to identify whether they have been affected by specific illnesses over the course of the previous year. As such, no distinction is made between different intensities nor frequencies and nor do we differentiate between different types of conditions.
} 
subjective health (see Dolan et al., 2008 for example) or with regards to the impact of disability (see Oswald and Powdthavee, 2008 inter alia). The results presented here show that illness has a negative association with wellbeing at time of incidence, with effects declining consistently across percentiles. From -0.050 at the 10 th percentile, it declines to -0.009 by the 90 th percentile. Beyond this initial effect, the negative impact upon wellbeing remains as a reported illness persists and there is no evidence of individuals adapting to their condition. Rather, the pattern is of illness duration being associated with an increasingly detrimental impact upon wellbeing and this is true across all percentile points). Reaching a maximum of -0.088 at the 10 th percentile, through -0.067 at the median, and 0.045 at the 90th percentile, these effects for the largest duration category (of five or more years after the event) are all statistically greater than the comparable initial effects. ${ }^{7}$

Interestingly, the negative effect of ill health increasing from an initial -0.009 to -0.045 if illness persists for $5+$ years at the 90th percentile stands in marked contrast to the effects identified by Gupta et al. (2015). Analysing the effect of illness using UK data from the British Household Panel Survey (BHPS), it was found that there were no identifiable effects of ill health at this point of the wellbeing distribution. Tellingly, their investigation used a GHQ-based measure of subjective wellbeing as its dependent variable. With insufficient variation in the life satisfaction measure contained in the BHPS (which is measured over a seven-point scale), a 37-point response on a Likert scale provided the necessary variation to employ a quantile regression estimator. While econometrically this provided the necessary variation for a tractable solution to examining the impact of illness across the subjective wellbeing distribution, the potential for GHQ-based measures (which explicitly include aspects of emotional and mental health) to be correlated with illness (and mental health issues in particular) exists. Using the life satisfaction response in HILDA, and our methodology of simulating a distribution

\footnotetext{
${ }^{7}$ There is no difference in the pattern of these results by gender, although interestingly the negative effects for women over the longer duration categories (in excess of 3 years) are significantly larger than they are for men at and below the median.
} 
(a)

10th Percentile - IIIness

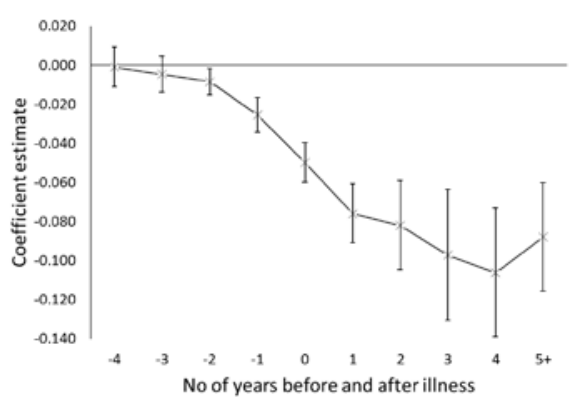

25th Percentile

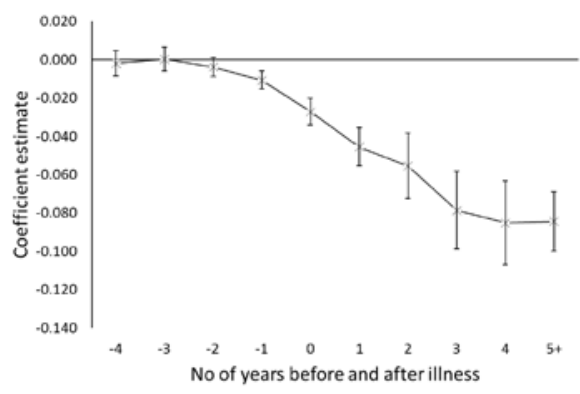

50th Percentile

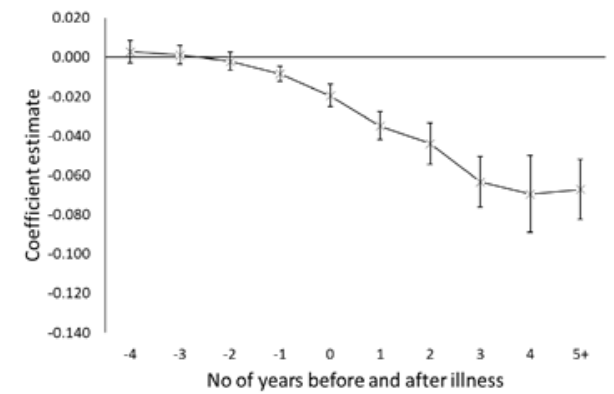

75th Percentile

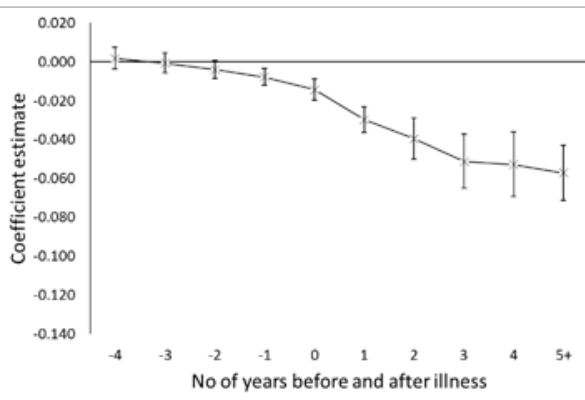

90th Percentile

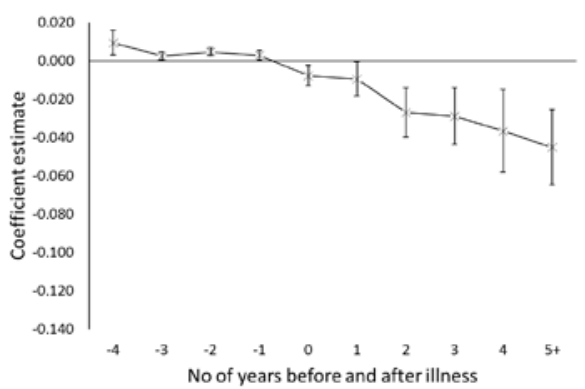

(b)

10th Percentile - Marriage

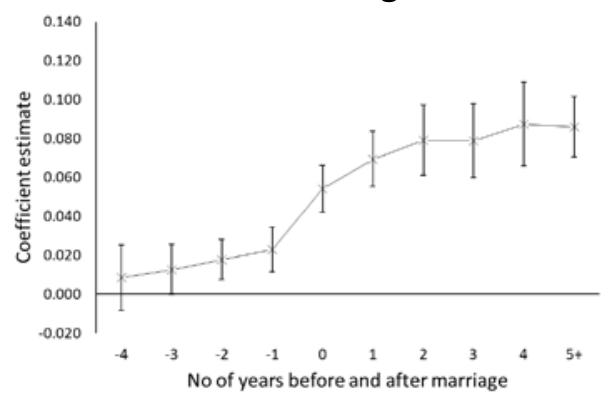

25th Percentile

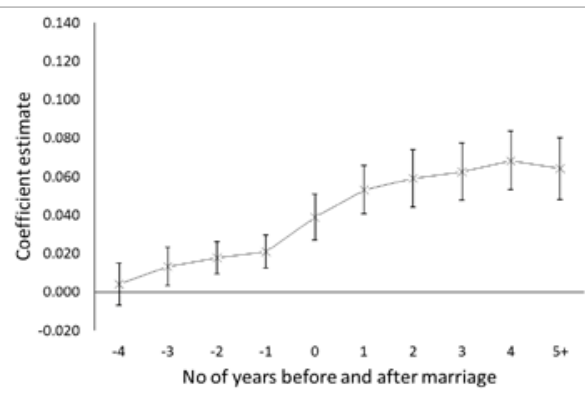

50th Percentile

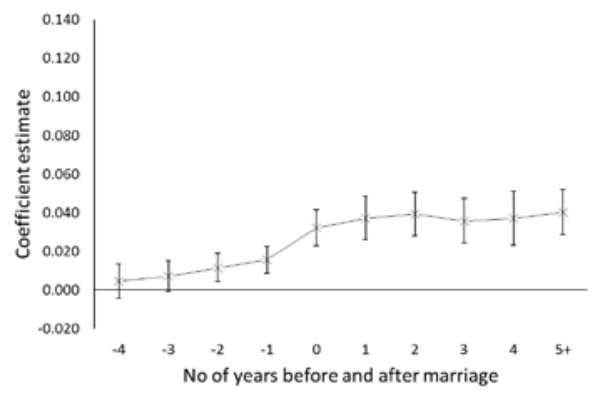

75th Percentile

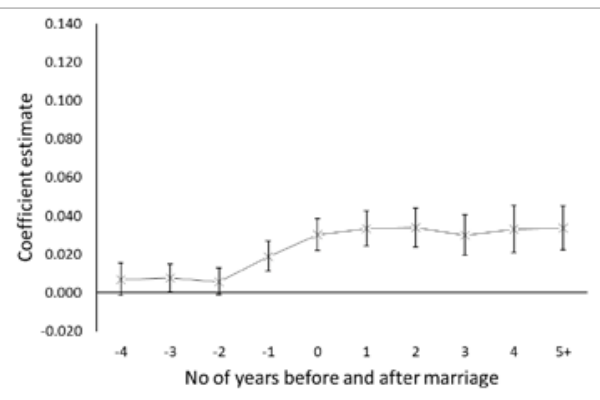

90th Percentile

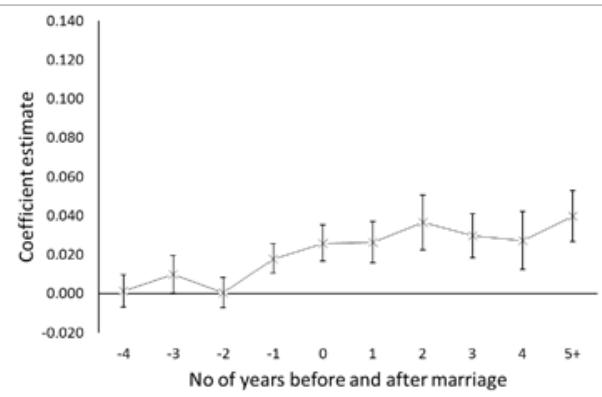

(c)

10th Percentile - Widowhood

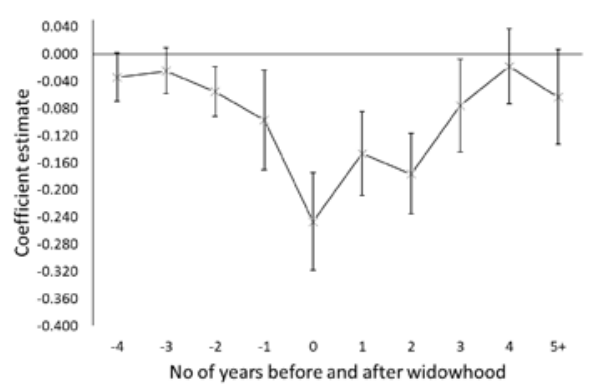

25th Percentile

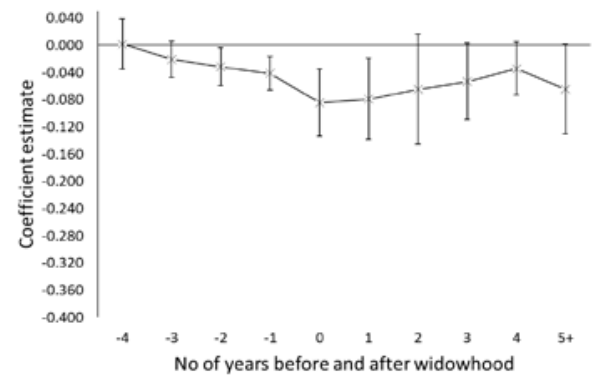

50th Percentile

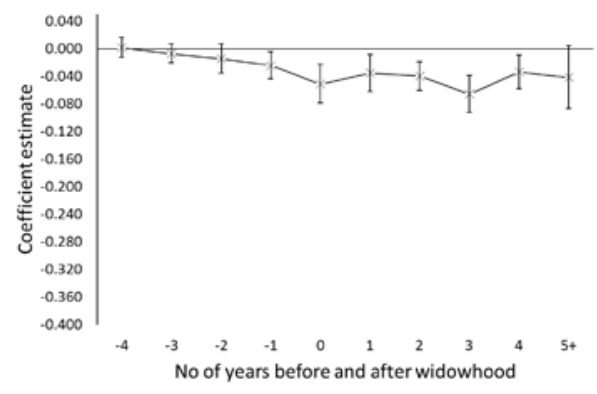

75th Percentile

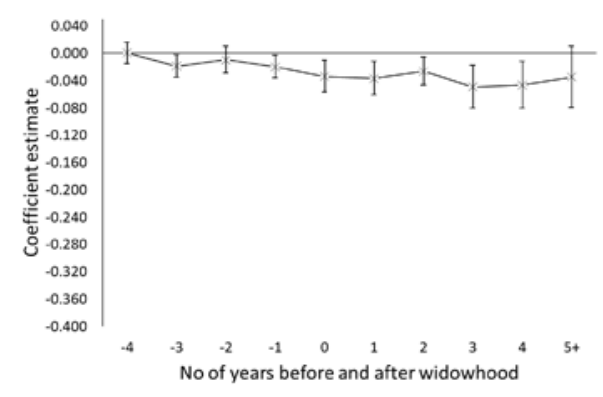

90th Percentile

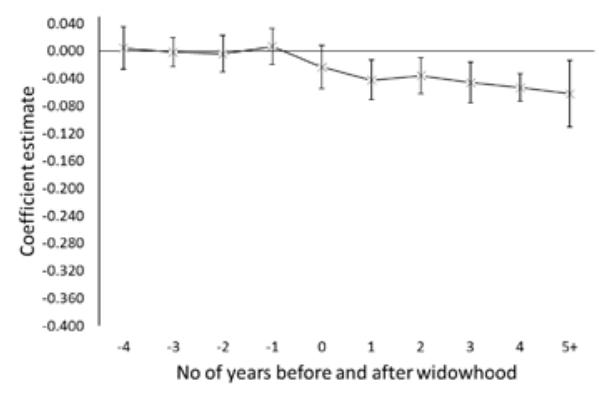


(d)

10th Percentile - Birth of Child

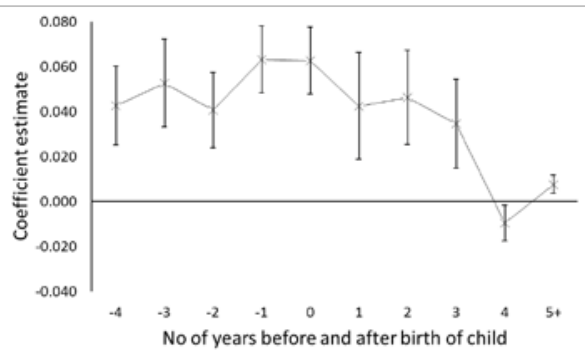

25th Percentile

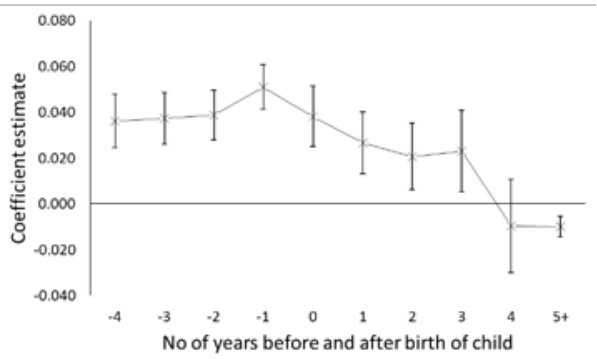

50th Percentile

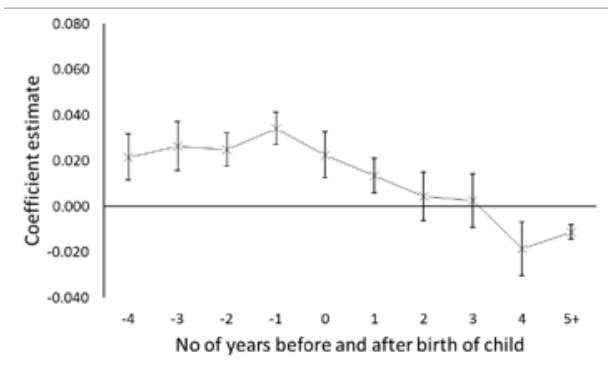

75th Percentile

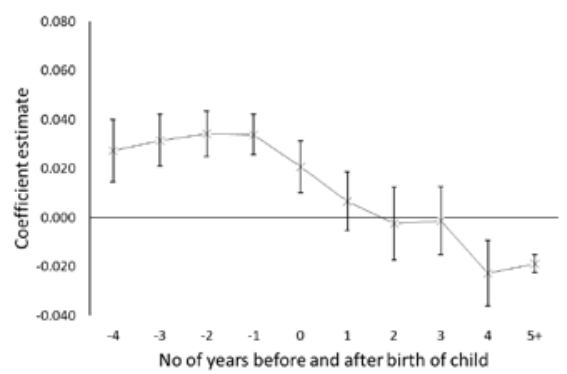

90th Percentile

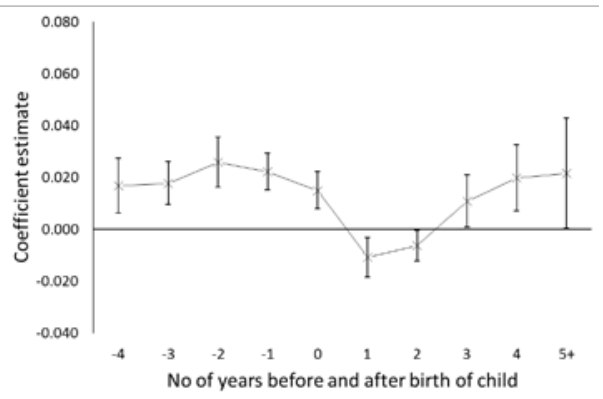

(e)

10th Percentile - Unemployment

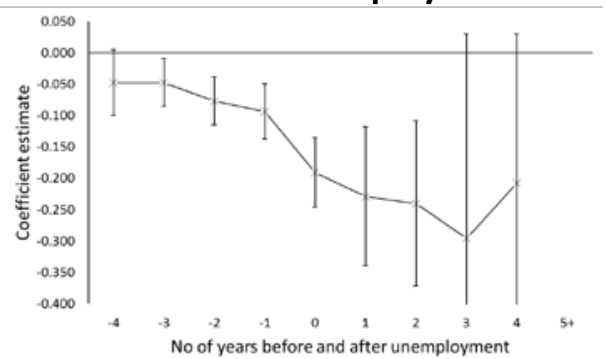

25th Percentile

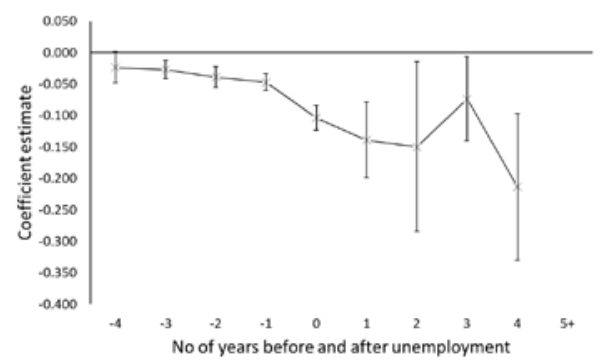

50th Percentile

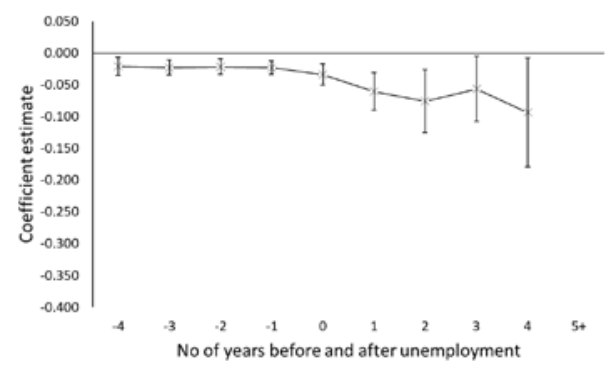

75th Percentile

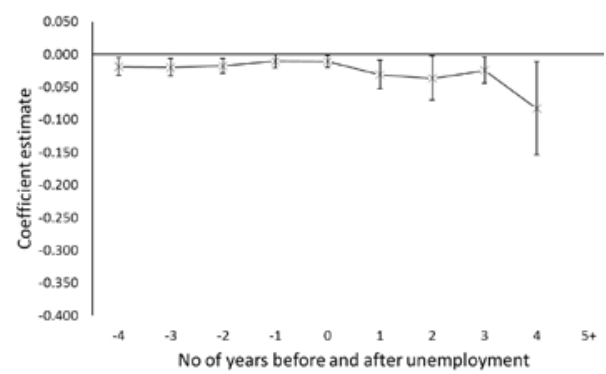

90th Percentile

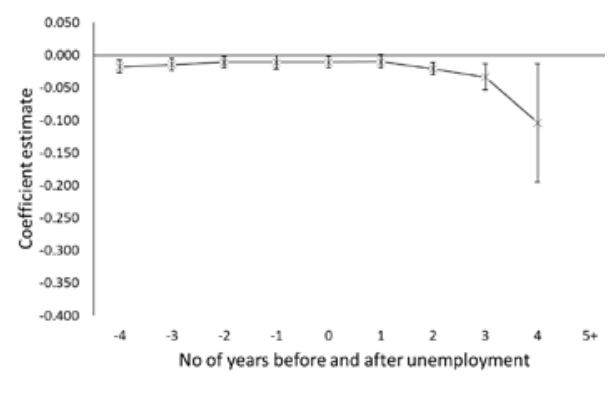


around their responses, avoids this problem and identifies substantial illness effects at the 90th percentile.

There is some evidence of a negative anticipatory effect into a spell of illness for all but those at the 90th percentile. These anticipatory effects are statistically significant only up to two years before the event and increase in magnitude as the onset of illness approaches and are most pronounced at the lowest 10th percentile. The implication would be that many episodes of illness are likely to impact upon wellbeing even before diagnosis and formal identification.

\subsection{Marriage}

Cross-section findings have consistently shown that married individuals are more satisfied with life than are their non-married counterparts (see Dolan et al., 2008 inter alia), although some longitudinal studies have found no long-lasting effect of marriage (see Lucas et al., 2003 inter alia). However, Easterlin (2003) questions such findings in the context of cohort-based analyses and posits that marriage has a positive effect upon wellbeing. Our own findings (see Figure 1, panel b) concur strongly with this latter stance, although we look at the formation of a long-term relationship and not explicitly the legal process of becoming married. Clearly, entering a long-term relationship has a positive effect upon subjective wellbeing and these effects persist over time. Outside of the 10th percentile where the estimated effect is 0.054 , effects are unrelated to the level of reported wellbeing and range from 0.039 at the 25th percentile to (a statistically indistinguishable) 0.026 at the 90th. Such positive findings are entirely consistent with the cultural and legal advantages that marriage brings with it, manifesting in social, physiological and psychological benefits (see Waite, 1995). ${ }^{8}$ Furthermore, it is likely that these substantial and positive estimates represent a lower bound to the explicit returns to

\footnotetext{
${ }^{8}$ Such results offer no support for a honeymoon effect, a well-established phenomenon in the psychological literature (see Lorber et al, 2015) where initially high marital satisfaction is short lived. It should be noted, though, that we look at a more general measure of life satisfaction as opposed to just satisfaction with marriage. As shown by Zanin(2013), the relationship between life satisfaction and various domains of life can be complex and we do not attempt to unpack it here.
} 
marriage (and not just cohabitation). Aggregating levels of life satisfaction over alternate marriage and cohabitation arrangements, Evans and Kelley (2004) found life-long marriage to be the most rewarding. Early divorce followed by an enduring marriage faired little worse. In contrast, divorce without remarriage, or long-lasting cohabitation without formal marriage, reduced the lifetime sum of subjective wellbeing by $4-12 \%$ for both men and women. ${ }^{9}$

There are also significant anticipation effects observed here that extend across the wellbeing distribution and are routinely observed a number of years (up to three) before the event. Given that by construction these effects are identified before a relationship has been formalised, it would suggest that it is the process of relationship formation that is a key driver to of these observed positive effects rather than the institution of marriage (or cohabitation) per se and these anticipatory effects tend to be greater at the 10 th and 25 th quantiles. ${ }^{10}$

\subsection{Widowhood}

The effect of widowhood upon wellbeing (see Figure 1, panel c) is largely intuitive. The death of a spouse has a detrimental effect upon welfare and negative outcomes persist for an extended period after the event. ${ }^{11}$ There are a number of key aspects to this process as identified from Figure 1. First, there are statistically significant and negative anticipation effects up to three years before a bereavement takes place across all percentile points below the 90th. Second, there is a significant negative impact upon wellbeing at time of event, with these effects more pronounced at both the 10th and 25 th percentiles ( -0.247 and -0.085 respectively) than at any of the other 50 th, 75 th or 90 th

\footnotetext{
${ }^{9}$ Bellido, Molina, Solaz and Stancanelli (2016) find that children conceived within first marriage deter divorce, while those conceived before first marriage destabilise marriage. While we do not explicitly test such a hypothesis, the inclusion of controls for number of children before and after marriage/cohabitation would capture the impact of increases in family size on life satisfaction (of which marital satisfaction would be a subset) and the hazard of relationship dissolution.

${ }^{10}$ The same pattern is repeated for both men and women and the magnitudes of the reported effects are in the main remarkably similar.

${ }^{11}$ Such findings are consistent with Mastekaasa (1994) who reported that widowhood was associated with lower subjective wellbeing in Norway and the effect was largest in the most recently widowed.
} 
percentiles $(-0.051,-0.034$ and -0.024 respectively). And third, widowhood has long-term scarring effects and these post-event effects increase in magnitude over time. Indeed, after 5 or more years widowhood still has a significantly negative impact upon wellbeing. These effects are largest towards the ends of the wellbeing distribution $(-0.063,-0.065$ and -0.062 at the 10 th, 25 th and 90 th percentiles respectively) but nonetheless still substantial at all percentile points - far in excess of point estimates for any other life event (except unemployment discussed later). Indeed, such an outcome reinforces the findings of existing research that bereavement of a spouse requires the greatest amount of readjustment when measured against other stressful life events (Stroebe and Stroebe, 2011). ${ }^{12}$ Wellbeing is likely to be reduced not only initially but over a period of time because of a loss of resources that accompanies widowhood (see Shapiro and Keyes, 2008 and Stack and Eshleman, 1998 inter alia). Such factors will encompass not only financial resources, which have been controlled for in the present analysis, but also emotional, social and instrumental (i.e. daily household activities) ones. $^{13}$

\subsection{Birth of a Child}

The effect of the birth of a child is shown in Figure 1 (panel d) and subtle patterns emerge from the data. ${ }^{14}$ Whereas there are uniform trends prior to the initial event with positive anticipation effects up to four years for all wellbeing levels, there is distinction across adaption at and above the median, and below. ${ }^{15}$ While initial effects are substantial and positive across the distribution (ranging from

\footnotetext{
${ }^{12}$ Similarly, Ory and Huijts (2015) also report that widows have lower levels of wellbeing than married individuals (and this varies across EU states and regions).

${ }^{13}$ The same pattern is evident for both men and women although interestingly the negative impact for men in the years after widowhood tend to be greater in magnitude than for women across all points of the wellbeing distribution.

${ }^{14}$ Set in the context of declining fertility in developed countries which has been associated with rising educational attainment ( $\mathrm{Ng}$ and Wang, 2020), a number of attempts have been made by the Australian government to increase fertility over the past decade. This has included a variety of incentives, such as family tax benefits, maternity tax offsets, initial cost offsets and government-funded maternity leave. Another possible explanation that accounts for declining Australian fertility is a quality-quantity trade-off (Bonner and Sarkar, 2018) where fewer children to support allows for greater resources to be devoted per child which can translate into superior lifetime outcomes.

${ }^{15}$ The birth of a child is identified as an increase in the number of dependent children of a respondent and no distinction is made between single and multiple births. However, those individuals who have multiple single
} 
0.063 at the 10 th percentile to 0.015 at the 90th percentile), these positive impacts fall away rapidly in the upper half of the wellbeing distribution. For each of the 50th and 75th percentiles any wellbeing advantage quickly drops away, such that the positive effect after one year $(0.013$ and 0.009 respectively), is indistinguishable from zero after two and is negative after four. An even starker deterioration is apparent at the 90th percentile, where there is no positive effect after the first year following birth these do return to initial levels after 3 years. In this sense, adaption to the birth of a child is rapid and complete. Such findings, where post-birth increases in wellbeing converge to prebirth levels soon after, have also been identified by Myrskylä and Margolis (2014) using UK and German data and by Frijters et al. (2011) using Australian data. ${ }^{16}$ By way of contrast, there is a longer run continuation of the initial positive effect at the 10th and 25th percentiles. In both instances, the wellbeing boost associate with the birth of a child is sustained throughout the first three years after the event before the previously discussed drop off is observed once again.

There is an interesting distinction in these effects by gender, in that women appear to be more affected by post-birth reductions in life satisfaction. While for men the positive association between birth and life satisfaction persists up to three years after birth, for women such effects last for only a single year at best. ${ }^{17}$ Such findings are consistent with sociological research which highlights the postbirth social isolation women may experience and the taking on of the role of primary caregiver when children are youngest and most demanding (see Simon, 1992).

births over the event horizon are excluded and so the post-event effects may be interpreted as solely adaption effects with no anticipatory element from any subsequent births. In reality, there are very few individuals who would have multiple single births given the rubric for the creation of the event histories (only around $5 \%$ of those reporting a birth at time $t$ ) and the inclusion of these observations does not change the nature of the results.

${ }^{16}$ In a much fuller examination of the effect of childbirth upon life satisfaction across multiple socio-demographic characteristics, Myrskylä and Margolis (2014) found that positive wellbeing effects were most pronounced with the birth of a first child. No distinction is drawn between ordering of births in our current work, though, and the effects identified are average effects across first and all subsequent births subject to the proviso that they appear within the constructed event window. However, a regressor is included for number of children and so the presence of prior siblings is implicitly controlled for in the presented results.

${ }^{17}$ Specifically, outside of the 10th percentile, the positive association between birth and life satisfaction persists up to three years after birth for men. In contrast for women, these positive effects disappear after just one year post event at the 25th and 50th percentiles and are not found at all at the 75th percentile and above. These results are available upon request. 


\subsection{Unemployment}

The effect of unemployment on wellbeing is shown in Figure 1 (panel e), with a detrimental impact at the time of the event evident across all percentile points. ${ }^{18}$ Such negative effects fit well with the large body of existing empirical evidence that emphasises the detrimental effect of unemployment upon wellbeing and happiness (see Clark and Oswald, 1994 and Winkelmann and Winkelmann, 1998 inter alia for overviews of this literature) and with the theoretical explanations of why unemployment results in negative psychological outcomes of Warr (1987) and Jahoda (1979). While the estimated initial effects are statistically significant at all percentile points, they are much more substantial in the lower half of the wellbeing distribution. Indeed, the -0.034 at the 50 th percentile compares to -0.104 at the 25 th percentile and -0.191 at the 10 th percentile. In contrast, the estimated effect at the 90th percentile is a much lower -0.011 . Thereafter, the detrimental effects of unemployment persist through the next four years. ${ }^{19}$ While again most pronounced at lower percentiles, the effects are nonetheless substantial across the distribution. After four years, these range from a minimum estimate of -0.083 at the 75 th percentile to a maximum -0.214 estimate at the 25 th percentile. Thus, there is no evidence to suggest that the effect of becoming unemployed is transitory and as such there is little evidence to imply that there is any sort of adaption, certainly over the time window studied here.

Such findings are consistent with the mean-based findings of Clark and Georgellis (2013) in the UK, those for Germany by Clark et al. (2008), those for Russia by Bauer et al. (2015), and the earlier Australian findings of Frijters et al. (2011). However, these new findings for Australia offer evidence that this phenomenon is equally true for those who have some of the highest, and some of the lowest,

\footnotetext{
${ }^{18}$ Unemployment is defined on the basis of an ILO definition, although the general patterns identified are consistent over alternative definitions of joblessness.

${ }^{19}$ Sample size considerations meant that is was not possible to calculate estimates for those in the $5+$ years category.
} 
levels of reported wellbeing. Moreover, the estimated wellbeing effects are of an order of magnitude in excess of those identified over all other life events, even for widowhood. As such, the point estimates for unemployment after four years are no less than other comparable estimates above the median and significantly greater in a statistical sense below the median. As also noted by Diener et al (2006), it is a perplexing finding that people are better able to adapt to unemployment than to severe life events such as widowhood. As explained by Hetschko et al. (2014), while other life events are truly irreversible, the social norm to be employed exerts continuous and unfulfilled pressure upon the unemployed to return to work - "it is the hope that keeps people unhappy while unemployed" (p.165).

With regard anticipation, these effects are more muted but again tend to be larger at lower percentile points. In this regard, it would suggest that the loss of a job that is integral to becoming unemployed does not tend to be a random or unanticipated event, and such anticipatory effects are evident for at least four years prior to unemployment. ${ }^{20}$ Although unemployment is in itself a distinct phenomenon, the possibility exists that there is a joint relationship between unemployment and illness, and it is this channel through which the unemployment effects are operating. Indeed, there is strong evidence to suggest a causal relationship between joblessness and both increased morbidity (see McKee-Ryan et al., 2005) and increased mortality (see Roelfs et el, 2011). To test this, we interacted the unemployment and illness dummy variables and modelled the anticipation and adaption to these in the same way as we have done previously where the coefficients upon this interaction term will pick out a differential effect of unemployment through ill health. Details of these results are given in Table 2.

\footnotetext{
${ }^{20}$ There are some subtle differences in these results by gender, although the same underlying pattern comes through for both men and women. For example, the negative anticipatory effects one year before the onset of unemployment are consistently greater in magnitude for men than they are for women. Similarly, while adaption effects are also routinely more negative for men than for women across all percentile points, many of the individual coefficient estimates are not significantly different at conventional level of statistical significance.
} 
While illness does exert some influence over the previously discussed results, its influence is limited, certainly post-event. More specifically, measured relative to a baseline of those who are unemployed (or who will be unemployed at time $t$ ) but report themselves to be in good health, the dual reporting of illness and unemployment has no role in accounting for any of the (negative) adaption effects. For each of the additional years as unemployment duration increases, the estimated coefficients are insignificant at all percentile points. Where there is scope for illness having an influence though is at the point of unemployment, where the magnitudes of the negative effects are the statistically greater for those also reporting illness at the median $(-0.075)$, the 25th percentile $(-0.100)$ and the 10th percentile $(-0.133)$. Thus, while the joint reporting of illness with periods out of work is an undeniable phenomenon, the evidence available here does not suggest that it is the route through which the substantial and continuing detrimental wellbeing effects identified as a spell of unemployment persists manifest themselves. Such findings fit well with the psychological scarring effects associated with involuntary job loss, encompassing the feelings of hopelessness and uselessness (Farre, Fasani and Mueller, 2018) and the reduction in feelings of personal efficacy and more aggravated selfperception of helplessness (Goldsmith, Veum and Darity, 1996) that accompany continued unemployment.

In contrast, there are substantial and significant anticipatory differences between those who report illness and those who do not. These are most evident in the year before unemployment, where anticipatory outcomes are far greater at the 10 th percentile $(-0.117)$ through to the 75 th percentile (0.029). ${ }^{21}$ While part of these strong anticipatory patterns can therefore be explained by illness, it is

\footnotetext{
${ }^{21}$ In an investigation of Okun's Law across OECD countries, Zanin (2014) found that younger cohorts, who are more likely to be employed on temporary contracts and are more exposed to the business cycle, have differential unemployment outcomes to other parts of the population. It is possible that the significant anticipatory effects of unemployment highlighted in our analysis are also driven by such cohorts. Sample size constraints meant that a meaningful analysis for younger age cohorts (specifically 16-24) is not viable, but it is possible to identify those who are employed continuously on permanent contracts and those who are employed continuously on casual contracts. While there is some evidence that the magnitudes of anticipatory effects are larger for those on temporary contracts, none of the individual point estimates are statistically different. These results are available
} 
not possible to say (with the data at hand) whether severity of an illness has a role to play in these findings. It may be that illness severity increases the hazard of unemployment, and it is this increased hazard that is associated with decreased wellbeing. Alternatively, it may be that more severe illnesses that make unemployment more likely directly impact upon wellbeing.

\begin{tabular}{|c|r|r|r|r|r|}
\cline { 2 - 6 } \multicolumn{1}{c|}{} & \multicolumn{1}{c|}{ 10th } & \multicolumn{1}{c|}{ 25th } & \multicolumn{1}{c|}{ 50th } & \multicolumn{1}{c|}{ 75th } & \multicolumn{1}{c|}{ 90th } \\
\hline$t-4$ & -0.088 & 0.016 & 0.011 & 0.016 & 0.009 \\
& $(0.085)$ & $(0.040)$ & $(0.021)$ & $(0.017)$ & $(0.023)$ \\
\hline$t-3$ & -0.021 & 0.013 & 0.006 & 0.017 & 0.013 \\
& $(0.045)$ & $(0.026)$ & $(0.013)$ & $(0.018)$ & $(0.011)$ \\
\hline$t-2$ & $-0.066^{*}$ & -0.037 & -0.006 & 0.006 & 0.004 \\
& $(0.037)$ & $(0.030)$ & $(0.014)$ & $(0.013)$ & $(0.011)$ \\
\hline$t-1$ & $-0.117^{* * *}$ & $-0.062^{* * *}$ & $-0.046^{* * *}$ & $-0.029^{* *}$ & -0.006 \\
& $(0.038)$ & $(0.019)$ & $0(.0013)$ & $(0.015)$ & $(0.015)$ \\
\hline$t$ & $-0.133^{*}$ & $-0.100^{* *}$ & $-0.075^{* *}$ & -0.035 & 0.000 \\
& $(0.075)$ & $(0.045)$ & $(0.035)$ & $(0.028)$ & $(0.024)$ \\
\hline$t+1$ & -0.199 & -0.097 & -0.013 & -0.029 & -0.003 \\
& $(0.179)$ & $(0.090)$ & $(0.029)$ & $(0.040)$ & $(0.033)$ \\
\hline$t+2$ & -0.345 & -0.090 & 0.022 & -0.077 & 0.017 \\
& $(0.506)$ & $(0.242)$ & $(0.065)$ & $(0.063)$ & $(0.074)$ \\
\hline$t+3$ & -0.034 & -0.150 & -0.133 & -0.081 & -0.022 \\
& $(0.246)$ & $(0.214)$ & $(0.262)$ & $(0.192)$ & $(0.065)$ \\
\hline$t+4$ & 0.196 & 0.098 & 0.269 & 0.276 & 0.262 \\
& $(0.176)$ & $(0.229)$ & $(0.257)$ & $(0.240)$ & $(0.165)$ \\
\hline$t+5+$ & $n a$ & $n a$ & $n a$ & $n a$ & $n a$ \\
& & & & & \\
\hline
\end{tabular}

Notes: ${ }^{+++} /{ }^{++} /{ }^{+}$denotes significance at the $99 \% / 95 \% / 90 \%$ confidence level; bootstrapped standard errors in parenthesis (500 repetitions); na denotes that estimates are not available due to small sample size.

Table 2: Anticipation and Adaption Effects of Joint Event of Unemployment with III Health by Percentile

\section{Concluding Comments}

upon request. A fuller investigation of Zanin's (2014) proposition might still shed light on the drivers of these results, but this is beyond the capabilities of the current data. 
While standardised quantitative measures of wellbeing are both available and under continual development, understanding and addressing the factors that can influence wellbeing is arguably a more pressing policy objective (see Marmot, 2010). This study fills this gap within the context of adaption and anticipation to major life events in an Australian setting. However, trying to improve the wellbeing of a nation with one-size-fits-all policies is not likely to be successful and the pandistributional and pan-event approach adopted clearly shows that while there are similar adjustment patterns across the subjective wellbeing distribution, the magnitude of the effects are quite different depending upon the life event identified. For all life aspects studied, though, immediate impacts tend to be greater at the lower end of the wellbeing distribution. A corollary of these results would suggest, therefore, that if we are concerned with gauging the impact and influence of life events on measured subjective wellbeing, the point at which we measure this is important.

With regard adaption to these changing life events, there is little evidence of reversion back to a baseline level of wellbeing for the majority of the scenarios analysed. Regardless of whether these events are associated with detrimental impacts upon welfare (such is the case for illness, widowhood and unemployment) or indeed a positive association (as in the case of marriage), the associated effects at time of occurrence persist over the reference window investigated here. The only proviso to this occurs for the birth of a child, and while there are undoubted positive (and substantial) influences identified, such associations fall away rapidly over the entire wellbeing distribution. Indeed, for the majority of individuals the whole process of family formation and addition appears to be a particularly stressful period in their life history, as welfare falls below baseline wellbeing after the initial halcyon event.

A common theme highlighted in the existing literature is the social ostracization that follows from traumatic events such as widowhood and empirically such phenomena have manifested themselves in detrimental wellbeing impacts in the analysis conducted here. And far from being concentrated 
among the most psychologically vulnerable with the lowest levels of wellbeing, these impacts are observed from the very lowest to the very highest levels of wellbeing. Indeed, the positive associations with companionship and social interaction is emphasised by the long-term increases in wellbeing that arise after marriage. As such, and thinking about the issue of widowhood in particular, policy that streamlines the helping functions provided by quasi-formal support organisations would be helpful. Products and services designed to lessen the feelings of isolation from community and society more generally would conceivably have greatest traction in mitigating the wellbeing decline experienced after bereavement. Policies aimed at social support systems, but more orientated towards the informal component, should be concerned with the development and promotion of schemes to help widows and widowers address specific problems (the lack of self-help groups for example).

In a similar vein, it is also interesting to note not only how quickly the positive effects associated with the birth of a child quickly dissipate but also how the wellbeing of women is detrimentally influenced after childbirth. This is a feature not as apparent for men, and it might be reasonably assumed that the greater childcare burden shouldered by women, time away from labour market engagement and the loss of financial autonomy might all be factors behind this. A greater emphasis on funded childcare places and promotion of local and community-led initiatives for new mothers would help alleviate the social isolation that is experienced by many post-natal. Indeed, given that the whole issue around childcare provision, in terms of availability, affordability and quality (see Daley and McGannon, 2014), and childcare subsidies (see Gong and Breunig, 2017) is currently a moot point on the Australian political agenda, such a call would seem timely.

It should be emphasised, though, that some of the very largest effects are observed not as a consequence of the trauma of bereavement but rather because of unemployment. And it is not the initial impact of losing a job that is so destructive to individual wellbeing, but rather the implications of remaining unemployed for an extended period of time. Research shows that the long-term 
unemployed fare worse in the labour market than those who are unemployed short-term (Abraham et al., 2019). They are state dependent, meaning that unemployment duration is related to the likelihood of remaining unemployed, with the obvious implication that such people get locked into a vicious circle of unemployment and ever deteriorating wellbeing. Policies aimed at tackling long-term unemployment are nothing new, but renewed focus at addressing and preventing entrenched joblessness would have substantial wellbeing implications.

Death and marital collapse are inevitable consequences of life, but initiatives can plausibly be pursued to mitigate the depressive impact that these have for some people. And we might also say that unemployment is an inevitable result of the efficient functioning of an economy and a natural churning of employment should not be feared, but the stagnating of the unemployed in a state of joblessness is more worrying. Given the rise in long-term unemployment more recently experienced since the Financial Crisis post-2008 in many western and industrialised economies, addressing this as a major policy concern will have appreciable benefits for aggregate wellbeing and mental health. ${ }^{22}$ Within the Australian context, wage subsidies, vocational training, employment counselling and job-making services have all been suggested as areas for government focus in spite of potentially substantial shortterm costs (see ACOSS, 2018).

While state dependency has been identified within the context of unemployment, our results also point to this phenomenon being pertinent for the onset of illness. The lack of adaption to health afflictions imply that individuals get locked into a lower state of wellbeing if illnesses persist and given the relationship between wellbeing and good health identified by Binder and Coad (2010) this is a

\footnotetext{
${ }^{22}$ While it might appear that Australia has been better placed to weather the storm of the 2008 Financial Crisis than many other industrialised economies and has not experienced the same increases in long-term unemployed as seen elsewhere, it would be bold to offer up their labour market interventions as exemplars of policies which should be used to combat a rise in long-term joblessness. Australia spends on average less than half of what similar countries spend on employment services and $15 \%$ of Newstart recipients have been on the payment for more than five years, with long-term unemployment having surged since the 1990s (ACOSS, 2018).
} 
worrying trend. Our own negative anticipatory effects before an illness has occurred would also add evidence to such a dynamic. And the fact that we have identified such effects, both pre- and postevent, across the entire wellbeing distribution would imply that the self-perpetuating correlation between ill health and wellbeing is not restricted to only those who are more psychologically vulnerable and less satisfied with life. Conceivably, renewed emphasis on supporting the psychological needs of those with chronic health conditions would help break this vicious circle but future research would be usefully deployed in identifying which specific conditions would provide the greatest impact along the lines of Binder and Coad (2013). 


\section{References}

Abraham, K., Haltiwanger, J., Sandusky, K. and Spletzer, J., 2019. The Consequences of Long-term Unemployment: Evidence from Linked Survey and Administrative Data. Industrial Labor Relations Review, 72, 266-299.

ACOSS, 2018. Faces of Unemployment, report by Australian Council of Social Service.

Ambrey, C. and Fleming, C., 2014. Life Satisfaction in Australia: Evidence from Ten Years of the HILDA Survey. Social Indicators Research, 115, 691-714.

Anusic, I., Yap, S. and Lucas, R., 2014. Does Personality Moderate Reaction and Adaption to Major Life Events? Analysis of Life Satisfaction and Affect in an Australian National Sample. Journal of Research in Personality, 51, 69-77.

Bauer, J., Cords, D., Sellung, R. and Souza-Poza, A., 2015. Effects of Different Life Events on Life Satisfaction in the Russian Longitudinal Monitoring Survey. Economics Letters, 129, 91-94.

Bellido, H., Molina, J., Solaz, A. and Stancanelli, E., 2016. Do Children of the First Marriage Deter Divorce?. Economic Modelling, 55, 15-31.

Binder, M. and Coad, A., 2010. An Examination of the Dynamics of Well-being and Life Events using Vector Autoregressions. Journal of Economic Behavior and Organization, 76, 353-371.

Binder, M. and Coad, A., 2011. From Average Joe's Happiness to Miserable Jane and Cheerful John: Using Quantile regressions to Analyze the Full Subjective Well-being Distribution. Journal of Economic Behavior and Organization, 79, 275-290.

Binder, M. and Coad, A., 2013. 'I'm Afraid I have Bad News for You ...' Estimating the Impact of Different Health Impairments on Subjective Well-being. Social Science and Medicine, 87, 155-167.

Bonner, S. and Sarkar, D., 2018. The Quality-Quantity Trade-Off Among Australian Children. Economic Modelling, 70, 383-389.

Brickman, P. and Campbell, D., 1971. Hedonic Relativism and Planning the Good Society. in Appley M. (ed.) Adaption-Level Theory, New York: Academic Press.

Brickman, P., Coates, D. and Janoff-Bulman, R., 1978. Lottery Winners and Accident Victims - is Happiness Relative?. Journal of Personality and Social Psychology, 36, 917-927.

Bonanno, G., Wortman, C., Lehman, D., Tweed, R. and Haring, M., 2002. Resilience to Loss and Chronic Grief: A Prospective Study from Preloss to 18-Months Postloss. Journal of Personality and Social Psychology, 83, 1150-1164.

Bonanno, G., Wortman, C. and Nesse, R., 2004. Prospective Patterns of Resilience and Maladjustment during Widowhood. Psychology and Aging, 19, 260-271.

Clark, A., Diener, E., Georgellis, Y. and Lucas, R. 2008., Lags and Leads in Life Satisfaction: A Test of the Baseline Hypothesis. Economic Journal, 118, F222-243. 
Clark, A. and Georgellis, Y., 2013. Back to Baseline in Britain: Adaption in the British Household Panel Survey. Economica, 80, 496-512.

Clark, A. and Oswald, A., 1994. Unhappiness and Unemployment. Economic Journal, 104, 648-659.

Cross, J., 2019. On the Reduced Macroeconomic Volatility of the Australian Economy: Good Policy or Good Luck?. Economic Modelling, 77, 174-186.

Daley, J. and McGannon, C., 2014. To Lift Economic Growth We Must Cut the Cost of Childcare, Gratton Institute, March 2014.

Diener, E., Lucas, R. and Scollon, C., 2006. Beyond the Hedonic Treadmill - Revising the Adaption Theory of Well-Being. American Psychologist, 61, 305-314.

Diener, E. and Ryan, K., 2009. Subjective Well-Being: A General Overview. South African Journal of Psychology, 39, 391-406.

Dolan, P., Peasgood, T. and White, M., 2008. Do We Really Know What Makes Us Happy? A Review of the Economic Literature on the Factors Associated with Subjective Well-Being. Journal of Economic Psychology, 29, 94-122.

Easterlin, R., 2003. Explaining Happiness. Proceedings of the National Academy of Sciences, 100, 11176-11183.

Evans, M. and Kelley, J., 2004. Effect of Family Structure on Life Satisfaction: Australian Evidence. Social Indicators Research, 69, 303-349.

Farre, L., Fasani, F. and Mueller, H., 2018. Feeling Useless: The Effect of Unemployment on Mental Health in the Great Recession. IZA Journal of Labor Economics, 7, 1-34.

Ferrer-i-Carbonell, A. and Frijters, P., 2004. How Important is Methodology for the Estimates of the Determinants of Happiness?. Economic Journal, 114, 641-59

Ferrer-i-Carbonell, A. and Van Praag, B., 2008. Do People Adapt to Changes in Income and Other Circumstances? The Discussion is not Finished yet. IAE-CSIC Working Paper 2008/5.

Frijters, P., Johnston, D., and Shields, M., 2011. Life Satisfaction Dynamics with Quarterly Life Event Data. The Scandinavian Journal of Economics, 113, 190-211.

Gardner, J. and Oswald, A., 2006. Do Divorcing Couples Become Happier by Breaking Up?. Journal of the Royal Statistical Society: Series A (Statistics in Society), 169, 319-336.

Goldsmith, A., Veum, J. and Darity, W., 1996. The Psychological Impact of Unemployment and Joblessness. Journal of Socio-Economics, 25, 333-358.

Gong, X. and Breunig, R., 2017. Childcare Assistance: Are Subsidies or Tax Credits Better?. Fiscal Studies, 38, 7-48.

Gupta, P., Mishra, T., O'Leary, N. and Parhi, M., 2015. The Distributional Effects of Adaption and Anticipation to III Health on Subjective Wellbeing. Economics Letters, 136, 99-102. 
Heady, B. and Muffels, R., 2017. Towards a Theory of Medium Term Life Satisfaction: Similar Results for Australia, Britain and Germany. Social Indicators Research, 134, 359-384.

Heady, B., Muffels, R. and Wagne,r G., 2010. Long-Running German Panel Survey Shows that Personal and Economic Choices, not just Genes, Matter for Happiness. PNAS, 107, 17922-17926.

Heady, B., Muffels, R. and Wagner, G., 2013. Choices which Change Life Satisfaction: Similar Results for Australia, Britain and Germany. Social Indicators Research, 112, 725-748.

Headey, B. and Wearing, A., 1989. Personality, Life Events, and Subjective Well-being: Toward a Dynamic Equilibrium Model. Journal of Personality and Social Psychology, 57, 731-739.

Helliwell, J., 2003. How's Life? Combining Individual and National Variables to Explain Subjective Wellbeing. Economic Modelling, 20, 331-360.

Hetschko, C., Knabe, A. and Schöb, R., 2014. Changing Identity: Retiring from Unemployment. Economic Journal, 124, 149-166.

Jahoda, M., 1979. The Impact of Unemployment in the 1930s and 1970s. British Psychological Society Bulletin, 32, 309-314.

Koenker, R., 2004. Quantile Regression for Longitudinal Data. Journal of Multivariate Analysis, 91, 7489.

Layard, R., Clark, A., Cornaglia, F., Powdthavee ,N. and Vernoit, J., 2014. What predicts a successful life? A life-course model of Well-being. Economic Journal, 124, F720-F738.

Lorber, M., Erlanger, A., Heyman, R. and O'Leary, K., 2015. The Honeymoon Effect: Does it Exist and Can it be Predicted?. Prevention Science, 16, 550-559.

Lucas, R., 2005. Time Does not Heal all Wounds: A Longitudinal Study of Reaction and Adaption to Divorce. Psychological Science, 16, 945-950.

Lucas, R., 2007. Long-term Disability is Associated with Lasting Changes in Subjective Well-being: Evidence from Two Nationally Representative Longitudinal Studies. Journal of Personality and Social Psychology, 92, 717-730.

Lucas, R. and Clark, A., 2006. Do People Really Adapt to Marriage?. Journal of Happiness Studies, 7, 405-426.

Lucas, R., Clark, A., Georgellis, Y. and Diener, E., 2003. Re-examining Adaption and the Set Point Model of Happiness: Reactions to Changes in Marital Status. Journal of Personality and Social Psychology, 84, 527-539.

Lucas, R., Clark, A., Georgellis, Y. and Diener, E., 2004. Unemployment Alters the Set-point for Life Satisfaction. Psychological Science, 15, 8-13.

Machado, J. and Santos Silva, J., 2005. Quantiles for Counts. Journal of the American Statistical Association, 100, 1226-1237. 
Manning, M., Ambrey, C. and Fleming, C., 2016. A Longitudinal Study of Indigenous Wellbeing in Australia. Journal of Happiness Studies, 17, 2503-2525.

Marmot, M., 2010. Fair Society, Healthy Lives (The Marmot Review). Institute of Health Equity, London.

Mastekaasa, A., 1994. The Subjective Well-being of the Previously Married: The Importance of Unmarried Cohabitation and Time Since Widowhood or Divorce. Social Forces, 73, 665-692.

McGregor, J. and Pouw, N., 2017. Towards an Economics of Well-Being. Cambridge Journal of Economics, 41, 1123-1142.

McKee-Ryan, F., Song, Z., Wanberg, C. and Kinicki, A., 2005. Psychological and Physical Well-Being During Unemployment: A Meta-Analytic Study. Journal of Applied Psychology, 90, 53-76.

McNamee, P. and Mendolia, S., 2014. The Effect of Chronic Pain on Life Satisfaction: Evidence from Australian Panel Data. Social Science and Medicine, 121, 65-73.

Melbourne Institute, 2016. The Household, Income and Labour Dynamics in Australia Survey: Selected Findings from Waves 1 to 14. Melbourne Institute of Applied Economic and Social Research Report.

Myrskylä, M. and Margolis, R., 2014. Happiness: Before and After the Kids. Demography, 51, 18431866.

Ng, W. and Wang, Y-C., 2020. Waiting as a Signal: Why Women are Delaying Fertility?. Economic Modelling, 87, 471-479.

ONS, 2011. Measuring What Matters. Office for National Statistics, London, July 2011.

Ory, B. and Huijts, T., 2015. Widowhood and Well-being in Europe: The Role of National and Regional Context. Journal of Marriage and Family, 77, 730-746.

Oswald, A. and Powdthavee, N., 2008. Does Happiness Adapt? A Longitudinal Study of Disability with Implications for Economists and Judges. Journal of Public Economics, 92, 1061-1077.

Paul, S. and Guilbert, D., 2013. Income-Happiness Paradox in Australia: Testing the Theories of Adaption and Social Comparison. Economic Modelling, 30, 900-910.

Powdthavee, N. and Wooden, M., 2015. Life Satisfaction and Sexual Minorities: Evidence from Australia and the United Kingdom. Journal of Economic Behavior and Organization, 116, 107-126.

Qari, S., 2014. Marriage, Adaption and Happiness: Are there Long-Lasting Gains to Marriage?. Journal of Behavioral and Experimental Economics, 50, 29-39.

Roelfs, D., Shor, E., Davidson, K. and Schwartz, J., 2011. Losing Life and Livelihood: a Systematic Review and Meta-Analysis of Unemployment and All-Cause Mortality. Social Science and Medicine, 72, 840854.

Shapiro, A. and Keyes, C. 2008., Marital Status and Social Well-being: are the Married Always Better Off?. Social Indicators Research, 88, 29-46. 
Shields, M., Wheatly Price, S. and Wooden, M., 2009. Life Satisfaction and the Economic and Social Characteristics of Neighbourhoods. Journal of Population Economics, 22, 421-433.

Silver, R., 1982. Coping with an Undesirable Life Event: A Study of Early Reactions to Physical Disability. unpublished doctoral thesis: Northwestern University, Evanston, IL.

Simon, R., 1992. Parental Role Strains, Salience of Paternal Identity and Gender Differences in Psychological Distress. Journal of Health and Social Behavior, 33, 25-35.

Stack, S. and Eshleman, J., 1998. Marital Status and Happiness: a 17-Nation Study. Journal of Marriage and the Family, 60, 527-536.

Stiglitz, R., Sen, A. and Fitoussi, J., 2009. Report of the Commission on the Measurement of Economic Performance and Social Progress. CMEPSP Report.

Stroebe, W. and Stroebe, M., 2011. Stress and Health. in Stroebe W. (ed.) Social Psychology and Health, 3rd edition, Open University Press.

Tosi, M. and Grundy, E., 2018. Returns Home by Children and Changes in Parents' Well-Being in Europe. Social Science and Medicine, 200, 99-106.

Warr, P., 1987. Work, Unemployment and Mental Health. Oxford University Press.

Waite, L., 1995. Does Marriage Matter?. Demography, 32, 483-507.

Wilson, W., 1967. Correlates of Avowed Happiness. Psychological Bulletin, 67, 294-306.

Winkelman, L. and Winkelman, R., 1998. Why are the Unemployed so Unhappy? Evidence from Panel Data. Economica, 65, 1-15.

Zanin, L., 2013. Detecting Unobserved Heterogeneity in the Relationship between Subjective WellBeing and Satisfaction in Various Domains of Life Using the REBUS-PLS Path Modelling Approach: A Case Study. Social Indicators Research, 110, 281-304.

Zanin, L., 2014. On Okun's Law in OECD Countries: An Analysis by Age Cohorts. Economics Letters, 125, 243-248. 


\begin{tabular}{|c|c|c|c|c|}
\hline $\begin{array}{l}\text { (a) before first observation of the } \\
\text { event at time } t\end{array}$ & \multicolumn{1}{l}{} \\
\hline $\boldsymbol{t}-\mathbf{4}$ & $\boldsymbol{t}-\mathbf{3}$ & $\boldsymbol{t}-\mathbf{2}$ & $\boldsymbol{t}-\mathbf{1}$ & $\boldsymbol{t}$ \\
\hline & & & 0 & 1 \\
\hline & & 0 & 0 & 1 \\
\hline & 0 & 0 & 0 & 1 \\
\hline 0 & 0 & 0 & 0 & 1 \\
\hline
\end{tabular}

\begin{tabular}{|c|c|c|c|c|c|}
\cline { 2 - 6 } \multicolumn{1}{c|}{} & $\begin{array}{l}\text { (b) after first observation of the } \\
\text { Event at time } t\end{array}$ \\
\hline $\boldsymbol{t}$ & $\boldsymbol{t + 1}$ & $\boldsymbol{t}+\mathbf{2}$ & $\boldsymbol{t + 3}$ & $\boldsymbol{t}+\mathbf{4}$ & $\boldsymbol{t}+\mathbf{5}(+)$ \\
\hline 1 & 0 & 0 & 0 & 0 & 0 \\
\hline 1 & 1 & 0 & 0 & 0 & 0 \\
\hline 1 & 1 & 1 & 0 & 0 & 0 \\
\hline 1 & 1 & 1 & 1 & 0 & 0 \\
\hline 1 & 1 & 1 & 1 & 1 & 0 \\
\hline 1 & 1 & 1 & 1 & 1 & 1 \\
\hline
\end{tabular}

Notes: 0 denotes that an event has not been reported; 1 denotes that an event has been reported; a blank cell implies that a respondent has not responded to the survey.

Appendix Figure 1: Schematic Representation of Data in Event Histories 


\begin{tabular}{|c|c|}
\hline & Definition \\
\hline Subjective Wellbeing & $\begin{array}{l}\text { Proxied by jittered response to life satisfaction question (How satisfied are } \\
\text { you with your life?) which is recorded on a scale of 1-10. }\end{array}$ \\
\hline Age & Age of the respondent in years. Entered in linear and quadratic form. \\
\hline Wave & $\begin{array}{l}\text { A series of dummy variables denoting the wave in which the respondent } \\
\text { was interviewed: wavex }(x=1 \ldots 14)\end{array}$ \\
\hline Household Income & Real net total household income in January 2014 prices. \\
\hline Employment Status & $\begin{array}{l}\text { A series of dummy variables denoting the employment status of the } \\
\text { respondent based on an ILO/ABS definition: } 1-\text { employed; } 2- \\
\text { unemployed; } 3 \text {-inactive. }\end{array}$ \\
\hline Qualifications & $\begin{array}{l}\text { A series of dummy variables denoting the highest educational } \\
\text { qualification of the respondent: } 1 \text { - year } 12 / 11 \text { or lower; } 2 \text { - certificate } \\
\text { III/IV, diploma or advanced diploma; } 3 \text { - bachelors or honours degree; } 4- \\
\text { postgraduate degree or graduate diploma/certificate. }\end{array}$ \\
\hline Marital Status & $\begin{array}{l}\text { A series of dummy variables denoting the marital status of the } \\
\text { respondent: } 1-\text { single (never married); } 2-\text { married or cohabitating; } 3- \\
\text { widowed/divorced/separated. }\end{array}$ \\
\hline Number of Children & The number of dependent children in the respondent's household. \\
\hline Illness & $\begin{array}{l}\text { A dummy variable denoting that the respondent has been affected by an } \\
\text { illness or disability in the previous } 12 \text { months. }\end{array}$ \\
\hline State & $\begin{array}{l}\text { A series of dummy variables denoting the state within which the } \\
\text { respondent resides: } 1 \text { - WA; } 2-N T ; 3-S A ; 4-V I C ; 5-N S W ; 6-A C T ; 7- \\
\text { QLD; } 8 \text { - TAS. }\end{array}$ \\
\hline Remoteness & $\begin{array}{l}\text { A dummy variable denoting the that respondent lives in a geographically } \\
\text { remote region. }\end{array}$ \\
\hline
\end{tabular}

Appendix Table 1: Variable Definitions 


\begin{tabular}{|c|c|c|c|c|c|c|c|c|c|c|c|c|c|c|c|}
\hline & \multicolumn{5}{|c|}{ A - Illness } & \multicolumn{5}{|c|}{ B - Marriage } & \multicolumn{5}{|c|}{ C - Widowhood } \\
\hline & 10th & 25th & 50th & 75th & 90th & 10th & 25th & 50th & 75th & 90th & 10th & 25th & 50th & 75th & 90th \\
\hline$t-4$ & $\begin{array}{l}.001 \\
.005)\end{array}$ & $\begin{array}{r}-0.002 \\
(0.003)\end{array}$ & $\begin{array}{r}0.003 \\
(0.003)\end{array}$ & $\begin{array}{r}0.002 \\
(0.003)\end{array}$ & $\begin{array}{r}0.009^{* * *} \\
(0.003)\end{array}$ & $\begin{array}{r}0.008 \\
(0.009)\end{array}$ & $\begin{array}{r}0.004 \\
(0.006)\end{array}$ & $\begin{array}{r}0.004 \\
(0.004)\end{array}$ & $\begin{array}{r}0.007 \\
(0.004)\end{array}$ & $\begin{array}{r}0.001 \\
(0.004)\end{array}$ & & $\begin{array}{r}0.002 \\
(0.019)\end{array}$ & $\begin{array}{r}0.002 \\
(0.007)\end{array}$ & $\begin{array}{r}0.000 \\
(0.008)\end{array}$ & $\begin{array}{r}0.004 \\
(0.016)\end{array}$ \\
\hline$t-3$ & & $\begin{array}{r}0.000 \\
(0.003) \\
\end{array}$ & & $\begin{array}{r}-0.001 \\
(0.003)\end{array}$ & & $\begin{array}{c}0.013^{*} \\
(0.007)\end{array}$ & $\begin{array}{r}0.013^{* * *} \\
(0.005)\end{array}$ & $\begin{array}{c}0.007^{*} \\
(0.004)\end{array}$ & $\begin{array}{l}0.008^{* *} \\
(0.004)\end{array}$ & $\begin{array}{l}0.010^{* *} \\
(0.005)\end{array}$ & $\begin{array}{r}-0.025 \\
(0.017) \\
\end{array}$ & $\begin{array}{r}-0.021 \\
(0.014)\end{array}$ & $\begin{array}{r}-0.007 \\
(0.007)\end{array}$ & $\begin{array}{r}-0.019^{* *} \\
(0.008)\end{array}$ & \\
\hline$t-2$ & $\begin{array}{c}-0.009^{* *} \\
(0.003)\end{array}$ & $\begin{array}{r}-0.004 \\
(0.003) \\
\end{array}$ & & $\begin{array}{l}-0.004^{*} \\
(0.002)\end{array}$ & $\begin{array}{l}0.005^{* *} \\
(0.001)\end{array}$ & $\begin{array}{r}0.018^{* * *} \\
(0.005)\end{array}$ & $\begin{array}{c}0.018^{* * *} \\
(0.004)\end{array}$ & $\begin{array}{c}0.011^{* * *} \\
(0.004)\end{array}$ & $\begin{array}{r}0.006 \\
(0.004) \\
\end{array}$ & $\begin{array}{r}0.000 \\
(0.004) \\
\end{array}$ & $\begin{array}{r}-0.056^{* * *} \\
(0.019) \\
\end{array}$ & $\begin{array}{c}-0.032^{* *} \\
(0.014) \\
\end{array}$ & & & $\begin{array}{r}0.004 \\
(0.014) \\
\end{array}$ \\
\hline$t-1$ & $\begin{array}{r}-0.026^{* * *} \\
(0.005) \\
\end{array}$ & $\begin{array}{r}-0.011^{* * *} \\
(0.002) \\
\end{array}$ & \begin{tabular}{|r|}
$-0.009^{* * *}$ \\
$(0.002)$ \\
\end{tabular} & \begin{tabular}{|r|}
$-0.008^{* * *}$ \\
$(0.002)$ \\
\end{tabular} & $\begin{array}{r}0.003 \\
(0.001) \\
\end{array}$ & $\begin{array}{r}0.023^{* * *} \\
(0.006) \\
\end{array}$ & $\begin{array}{c}0.021^{* * *} \\
(0.004)\end{array}$ & $\begin{array}{r}0.016^{* * *} \\
(0.004) \\
\end{array}$ & $\begin{array}{r}0.019^{* * *} \\
(0.004)\end{array}$ & $\begin{array}{c}0.018^{* * *} \\
(0.004) \\
\end{array}$ & $\begin{array}{r}-0.097^{* * *} \\
(0.038) \\
\end{array}$ & $\begin{array}{r}-0.041^{* * *} \\
(0.013) \\
\end{array}$ & $\begin{array}{c}-0.024^{* *} \\
(0.010) \\
\end{array}$ & & $\begin{array}{r}0.007 \\
(0.013) \\
\end{array}$ \\
\hline$t$ & $\begin{array}{r}-0.050^{* * *} \\
(0.005) \\
\end{array}$ & \begin{tabular}{|c|}
$-0.027^{* * *}$ \\
$(0.004)$ \\
\end{tabular} & \begin{tabular}{|c|}
$-0.020^{* * *}$ \\
$(0.003)$ \\
\end{tabular} & \begin{tabular}{|r|}
$-0.014^{* * *}$ \\
$(0.003)$ \\
\end{tabular} & \begin{tabular}{|r|}
$-0.008^{* * *}$ \\
$(0.003)$ \\
\end{tabular} & $\begin{array}{r}0.054^{* * *} \\
(0.006) \\
\end{array}$ & $\begin{array}{r}0.039^{* * *} \\
(0.006) \\
\end{array}$ & $\begin{array}{r}0.032^{* * *} \\
(0.005) \\
\end{array}$ & $\begin{array}{r}0.030^{* * *} \\
(0.004) \\
\end{array}$ & $\begin{array}{r}0.026^{* * *} \\
(0.005) \\
\end{array}$ & \begin{tabular}{|r}
$-0.247^{* * *}$ \\
$(0.037)$ \\
\end{tabular} & \begin{tabular}{|r|}
$-0.085^{* * *}$ \\
$(0.025)$ \\
\end{tabular} & \begin{tabular}{|r}
$-0.051^{* * *}$ \\
$(0.014)$ \\
\end{tabular} & \begin{tabular}{|c|}
$-0.034^{* * *}$ \\
$(0.012)$ \\
\end{tabular} & $\begin{array}{r}-0.024 \\
(0.016) \\
\end{array}$ \\
\hline$t+1$ & $\begin{array}{r}-0.076^{* * *} \\
(0.008) \\
\end{array}$ & $\begin{array}{r}-0.046^{* * *} \\
(0.005) \\
\end{array}$ & \begin{tabular}{|r|}
$-0.035^{* * *}$ \\
$(0.004)$ \\
\end{tabular} & \begin{tabular}{|r|}
$-0.030^{* * *}$ \\
$(0.003)$ \\
\end{tabular} & $\begin{array}{r}-0.010^{* *} \\
(0.005)\end{array}$ & $\begin{array}{r}0.069^{* * *} \\
(0.007) \\
\end{array}$ & $\begin{array}{r}0.053^{* * *} \\
(0.006) \\
\end{array}$ & $\begin{array}{r}0.037^{* * *} \\
(0.006) \\
\end{array}$ & $\begin{array}{r}0.033^{* * *} \\
(0.005)\end{array}$ & & & \begin{tabular}{|r|}
$-0.079^{* * *}$ \\
$(0.030)$ \\
\end{tabular} & & \begin{tabular}{|r|}
$-0.037^{* * *}$ \\
$(0.012)$ \\
\end{tabular} & \\
\hline$t+2$ & $\begin{array}{r}-0.082^{* * *} \\
(0.012) \\
\end{array}$ & \begin{tabular}{|r|}
$-0.056^{* * *}$ \\
$(0.009)$ \\
\end{tabular} & \begin{tabular}{|r|}
$-0.044^{* * *}$ \\
$(0.005)$ \\
\end{tabular} & \begin{tabular}{|r|}
$-0.040^{* * *}$ \\
$(0.005)$ \\
\end{tabular} & \begin{tabular}{|r|}
$-0.027^{* * *}$ \\
$(0.007)$ \\
\end{tabular} & $\begin{array}{r}0.079^{* * *} \\
(0.009) \\
\end{array}$ & $\begin{array}{r}0.059^{* * *} \\
(0.008) \\
\end{array}$ & $\begin{array}{r}0.039^{* * *} \\
(0.006) \\
\end{array}$ & $\begin{array}{r}0.034^{* * *} \\
(0.005)\end{array}$ & $\begin{array}{r}0.036^{* * *} \\
(0.007)\end{array}$ & $\begin{array}{r}-0.177^{* * *} \\
(0.030) \\
\end{array}$ & $\begin{array}{r}-0.065 \\
(0.041) \\
\end{array}$ & $\begin{array}{r}-0.040^{* * *} \\
(0.011) \\
\end{array}$ & $\begin{array}{c}-0.026^{* *} \\
(0.010) \\
\end{array}$ & $\begin{array}{r}-0.036^{* * *} \\
(0.013) \\
\end{array}$ \\
\hline$t+3$ & $\begin{array}{r}-0.097^{* * *} \\
(0.017) \\
\end{array}$ & \begin{tabular}{|r|}
$-0.079^{* * *}$ \\
$(0.010)$ \\
\end{tabular} & \begin{tabular}{|r|}
$-0.063^{* * *}$ \\
$(0.007)$ \\
\end{tabular} & \begin{tabular}{|r|}
$-0.051^{* * *}$ \\
$(0.007)$ \\
\end{tabular} & \begin{tabular}{|r|}
$-0.029^{* * *}$ \\
$(0.008)$ \\
\end{tabular} & $\begin{array}{r}0.079^{* * *} \\
(0.010)\end{array}$ & $\begin{array}{r}0.062^{* * *} \\
(0.008) \\
\end{array}$ & $\begin{array}{r}0.036^{* * *} \\
(0.006) \\
\end{array}$ & $\begin{array}{r}0.030^{* * *} \\
(0.005) \\
\end{array}$ & $\begin{array}{r}0.030^{* * *} \\
(0.006) \\
\end{array}$ & $\begin{array}{c}-0.076^{* *} \\
(0.035) \\
\end{array}$ & $\begin{array}{l}-0.053^{*} \\
(0.029) \\
\end{array}$ & $\begin{array}{r}-0.066^{* * *} \\
(0.014) \\
\end{array}$ & \begin{tabular}{|r|}
$-0.049^{* * *}$ \\
$(0.016)$ \\
\end{tabular} & $\begin{array}{r}-0.046^{* * *} \\
(0.015) \\
\end{array}$ \\
\hline$t+4$ & $\begin{array}{r}-0.106^{* * *} \\
(0.017) \\
\end{array}$ & \begin{tabular}{|r|}
$-0.085^{* * *}$ \\
$(0.011)$ \\
\end{tabular} & \begin{tabular}{|r|}
$-0.070^{* * *}$ \\
$(0.010)$ \\
\end{tabular} & \begin{tabular}{|r|}
$-0.053^{* * *}$ \\
$(0.008)$ \\
\end{tabular} & \begin{tabular}{|r|}
$-0.037^{* * *}$ \\
$(0.011)$ \\
\end{tabular} & $\begin{array}{r}0.087^{* * *} \\
(0.011) \\
\end{array}$ & $\begin{array}{r}0.068^{* * *} \\
(0.008) \\
\end{array}$ & $\begin{array}{r}0.037^{* * *} \\
(0.007) \\
\end{array}$ & $\begin{array}{r}0.033^{* * *} \\
(0.006) \\
\end{array}$ & $\begin{array}{r}0.027^{* * *} \\
(0.008) \\
\end{array}$ & $\begin{array}{r}-0.018 \\
(0.028) \\
\end{array}$ & $\begin{array}{c}-0.035^{*} \\
(0.020) \\
\end{array}$ & $\begin{array}{r}-0.034^{* * *} \\
(0.012) \\
\end{array}$ & \begin{tabular}{|r|}
$-0.046^{* * *}$ \\
$(0.017)$ \\
\end{tabular} & $\begin{array}{r}-0.054^{* * *} \\
(0.010) \\
\end{array}$ \\
\hline$t+5+$ & $\begin{array}{r}-0.088^{* * *} \\
(0.014)\end{array}$ & \begin{tabular}{|r|}
$-0.085^{* * *}$ \\
$(0.008)$ \\
\end{tabular} & \begin{tabular}{|r|}
$-0.067^{* * *}$ \\
$(0.008)$
\end{tabular} & $\begin{array}{r}-0.057^{* * *} \\
(0.007) \\
\end{array}$ & \begin{tabular}{|r|}
$-0.045^{* * *}$ \\
$(0.010)$ \\
\end{tabular} & $\begin{array}{r}0.086^{* * *} \\
(0.008)\end{array}$ & $\begin{array}{r}0.064^{* * *} \\
(0.008)\end{array}$ & $\begin{array}{r}0.040^{* * *} \\
(0.006)\end{array}$ & $\begin{array}{r}0.034^{* * *} \\
(0.006)\end{array}$ & $\begin{array}{r}0.040^{* * *} \\
(0.007)\end{array}$ & $\begin{array}{l}-0.063^{*} \\
(0.036)\end{array}$ & $\begin{array}{c}-0.065^{*} \\
(0.034)\end{array}$ & $\begin{array}{l}-0.042^{*} \\
(0.023) \\
\end{array}$ & $\begin{array}{r}-0.035 \\
(0.023) \\
\end{array}$ & $\begin{array}{r}-0.062^{* * *} \\
(0.025) \\
\end{array}$ \\
\hline
\end{tabular}




\begin{tabular}{|c|c|c|c|c|c|c|c|c|c|c|}
\hline & \multicolumn{5}{|c|}{ D - Birth of Child } & \multicolumn{5}{|c|}{ E - Unemployment } \\
\hline & 10th & 25th & 50th & 75th & 90th & 10th & 25th & 50th & 75th & 90th \\
\hline \multirow{2}{*}{$t-4$} & $0.043^{* * *}$ & $0.036^{* * *}$ & $0.022^{* * *}$ & $0.027^{* * *}$ & $0.017^{* * *}$ & $-0.048^{*}$ & $-0.024^{*}$ & $-0.021^{* * *}$ & $-0.019^{* * *}$ & $-0.018^{* * *}$ \\
\hline & $(0.009)$ & $(0.006)$ & $(0.005)$ & $(0.007)$ & $(0.005)$ & $(0.004)$ & $(0.013)$ & $(0.007)$ & $(0.007)$ & $(0.005)$ \\
\hline \multirow{2}{*}{$t-3$} & $0.053^{* * *}$ & $0.037^{* * *}$ & $0.026^{* * *}$ & $0.031^{* * *}$ & $0.018^{* * *}$ & $-0.048^{* *}$ & $-0.027^{* * *}$ & $-0.023^{* * *}$ & $-0.020^{* * *}$ & $-0.015^{* * *}$ \\
\hline & $(0.010)$ & $(0.006)$ & $(0.005)$ & $(0.005)$ & $(0.004)$ & $(0.010)$ & $(0.008)$ & $(0.006)$ & $(0.007)$ & $(0.005)$ \\
\hline \multirow{2}{*}{$t-2$} & $0.041^{* * *}$ & $0.039^{* * *}$ & $0.025^{* * *}$ & $0.034^{* * *}$ & $0.026^{* * *}$ & $-0.077^{* * *}$ & $-0.039^{* * *}$ & $-0.022^{* * *}$ & $-0.018^{* * *}$ & $-0.011^{* *}$ \\
\hline & $(0.009)$ & $(0.006)$ & $(0.004)$ & $(0.005)$ & $(0.005)$ & $(0.018)$ & $(0.008)$ & $(0.006)$ & $(0.006)$ & $(0.005)$ \\
\hline \multirow{2}{*}{$t-1$} & $0.063^{* * *}$ & $0.051^{* * *}$ & $0.034^{* * *}$ & $0.034^{* * *}$ & $0.022^{* * *}$ & $-0.094^{* * *}$ & $-0.047^{* * *}$ & $-0.023^{* * *}$ & $-0.011^{* *}$ & $-0.011^{* *}$ \\
\hline & $(0.008)$ & $(0.005)$ & $(0.004)$ & $(0.004)$ & $(0.004)$ & $(0.005)$ & $(0.007)$ & (0.005) & $(0.005)$ & $(0.005)$ \\
\hline \multirow{2}{*}{$t$} & $0.063^{* * *}$ & $0.038^{* * *}$ & $0.023^{* * *}$ & $0.021^{* * *}$ & $0.015^{* * *}$ & $-0.191^{* * *}$ & $-0.104^{* * *}$ & $-0.034^{* * *}$ & $-0.011^{* *}$ & $-0.011^{* *}$ \\
\hline & $(0.008)$ & $(0.007)$ & $(0.005)$ & $(0.005)$ & $(0.004)$ & $(0.028)$ & $(0.010)$ & $(0.008)$ & $(0.005)$ & $(0.005)$ \\
\hline \multirow{2}{*}{$t+1$} & $0.042^{* * *}$ & $0.027^{* * *}$ & $0.013^{* * *}$ & 0.007 & $-0.011^{* * *}$ & $-0.229^{* * *}$ & $-0.139^{* * *}$ & $-0.061^{* * *}$ & $-0.031^{* * *}$ & $-0.010^{* *}$ \\
\hline & $(0.012)$ & $(0.007)$ & $(0.004)$ & $(0.006)$ & $(0.004)$ & $(0.031)$ & (0.031) & $(0.015)$ & $(0.011)$ & $(0.005)$ \\
\hline \multirow{2}{*}{$t+2$} & $0.046^{* * *}$ & $0.021^{* * *}$ & 0.004 & -0.003 & $-0.006^{* *}$ & $-0.240^{* * *}$ & $-0.150^{* *}$ & $-0.076^{* * *}$ & $-0.037^{* *}$ & $-0.021^{* * *}$ \\
\hline & $(0.011)$ & $(0.007)$ & $(0.005)$ & $(0.008)$ & $(0.003)$ & $(0.046)$ & $(0.069)$ & $(0.025)$ & $(0.017)$ & $(0.005)$ \\
\hline \multirow[t]{2}{*}{$t+3$} & $0.035^{* * *}$ & $0.023^{* *}$ & 0.003 & -0.001 & $0.011^{* *}$ & $-0.295^{*}$ & $-0.074^{* *}$ & $\mid-0.057^{* *}$ & $-0.025^{* *}$ & $-0.034^{* * *}$ \\
\hline & $(0.010)$ & $(0.009)$ & $(0.006)$ & $(0.007)$ & $(0.005)$ & $(0.217)$ & $(0.034)$ & $(0.026)$ & $(0.010)$ & $(0.010)$ \\
\hline \multirow{2}{*}{$t+4$} & $-0.010^{* *}$ & -0.010 & $-0.019^{* * *}$ & $-0.023^{* * *}$ & $0.020^{* * *}$ & $-0.208^{*}$ & $-0.214^{* * *}$ & $-0.094^{* *}$ & $-0.083^{* *}$ & $-0.104^{* *}$ \\
\hline & $(0.004)$ & $(0.010)$ & $(0.006)$ & $(0.007)$ & $(0.007)$ & $(0.016)$ & $(0.060)$ & $(0.044)$ & $(0.036)$ & $(0.046)$ \\
\hline \multirow[t]{2}{*}{$t+5+$} & $0.008^{* * *}$ & $-0.010^{* * *}$ & $-0.011^{* * *}$ & $-0.019^{* * *}$ & $0.022^{* *}$ & $n a$ & $n a$ & $n a$ & $n a$ & $n a$ \\
\hline & $(0.002)$ & $(0.002)$ & $(0.002)$ & $(0.002)$ & $(0.011)$ & & & & & \\
\hline
\end{tabular}

Notes: ${ }^{+++} /{ }^{++} /{ }^{+}$denotes significance at the $99 \% / 95 \% / 90 \%$ confidence level; bootstrapped standard errors in parenthesis (500 repetitions); $n a$ denotes that estimates are not available due to small sample size.

\section{Appendix Table 2: Anticipation and Adaption Effects of Life Events on Life Satisfaction by Percentile}

